\title{
The Klippel-Trenaunay Syndrome
}

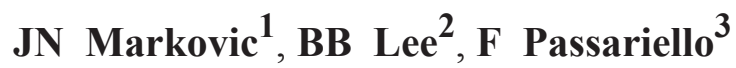

${ }^{1}$ Department of Surgery, Division of Vascular Surgery, Duke University Medical Center. Durham, NC 27710, USA. Office Phone: +1-919-681-2223

${ }^{2}$ Professor of Surgery and Director, Center for the Lymphedema and Vascular Malformations, Division of Vascular Surgery, Department of Surgery, George Washington University Medical Center, Washington, DC 20037, USA.

${ }^{3}$ Fondazione Vasculab ONLUS, via Francesco Cilea 280 - 80127 Naples, Italy

The official report of the KTrenaunay Vasculab Debate, held on the Internet, Vasculab List, on May 1-21, 2016 (unmoderated session: May 22-28, 2016. Discussant: Byung Boong Lee, Moderator: Fausto Passariello, Panel Experts: Miguel Angel Amore, Iris Baumgartner, NingFei Liu, Jovan Markovic, Raul Mattassi, Kurosh Parsi, Massimo Vaghi. submitted: Jan 22, 2017, accepted: Mar 23, 2017, EPub Ahead of Print: Apr 22, 2017, published: May 1, 2017

Conflict of interest: None

DOI: 10.24019/jtavr.11 - Corresponding author: Prof. Byung Boong Lee, bblee38@comcast.net

(C) 2016 Fondazione Vasculab impresa sociale ONLUS. All rights reserved.

Abstract The Klippel-Trenaunay Syndrome (KTS) includes congenital, low flow vascular malformation(s) that leads to structural and functional anomalies of the vascular system characterized by variability of presenting symptoms and often unpredictable clinical course. Traditionally described pathognomonic triad of findings in KTS patients are capillary malformation, venous malformation, and bone and/or soft tissue hypertrophy. KTS frequently includes the presence of lymphatic malformation(s), as well. Historically, the management of KTS was hampered by the lack of understanding of underlying hemodynamics and pathophysiology responsible for development and progression of KTS symptoms, confusing nomenclature which characterized majority of the early literature discussing KTS, as well as by the absence of established guidelines for KTS management. A relatively recent advancement in the diagnostic and treatment modalities have resulted in better understanding of the pathophysiology and natural history of KTS and represents a fertile environment for improved management of these patients. Multidisciplinary approach and diagnostic algorithm utilized to distinguish vascular malformations from vascular tumors, arterio-venous lesions from low flow vascular malformations have been validated as clinically applicable for making an accurate anatomical and hemodynamic assessment of the lesions found in KTS and serve as a basis for proper treatment selection. It has to be emphasized that treatment of majority KTS patients is palliative and goal oriented. In this manuscript we describe diagnostic protocols and therapeutic algorithms which results in favorable outcomes with an acceptable complication rates in the management of this frequently challenging patient population.

Keywords Klippel-Trenaunay
$\begin{aligned} & \text { Congenital Vyscular Malformations, } \\ & \text { Venous }\end{aligned}$
Malformations, Lateral Marginal Vein, Sclerotherapy
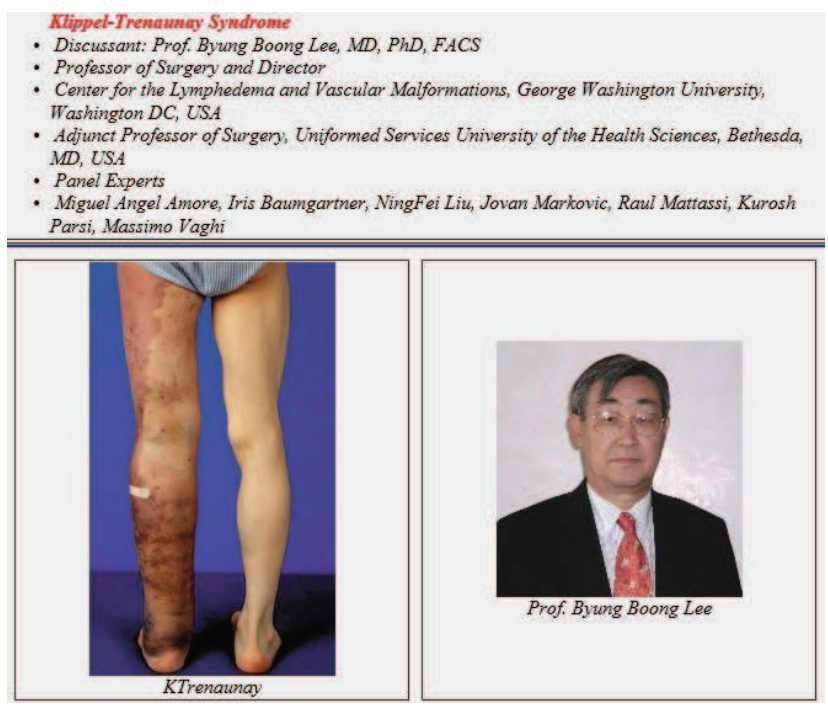

Figure 1 - The KTrenaunay webpage. DOI: 10.24019/2016.KTrenaunay 


\begin{tabular}{|c|c|}
\hline & Classification \\
\hline KTS & Klippel-Trenaunay Syndrome \\
\hline KTW & $\begin{array}{l}\text { Klippel-Trenaunay-Weber syndrome } \\
\text { (obsolete term) }\end{array}$ \\
\hline PW & Parkes-Weber \\
\hline PWS & Parkes-Weber Syndrome \\
\hline VBS & vascular bone syndrome \\
\hline CVM & Congenital Vascular malformation \\
\hline AVM & Arterial-Venous malformation \\
\hline $\mathrm{CM}$ & Capillary malformation or port wine stain \\
\hline VM & Venous malformation \\
\hline LM & Lymphatic malformation \\
\hline FAVA & Fibro-Adipose Vascular Anomaly \\
\hline HLM & Hemolymphatic Malformation \\
\hline MV & Marginal Vein \\
\hline GI & Gastro-Intestinal \\
\hline GU & Gastro-Urinary \\
\hline VLM & Veno-Lymphatic Malformation \\
\hline CLOVES & $\begin{array}{l}\text { CLOVES syndrome (representing each } \\
\text { component) } \\
\text { (C)ongenital, (L)ipomatous, (O)vergrowth, } \\
\text { (V)ascular malformation, (E)pidermal } \\
\text { nevus, (S)coliosis }\end{array}$ \\
\hline ISSVA & $\begin{array}{l}\text { International Society for the Study of } \\
\text { Vascular Anomalies }\end{array}$ \\
\hline IUP & International Union of Phlebology \\
\hline LEC & Lymphatic endothelial cells \\
\hline LIC & localized intravascular coagulation \\
\hline
\end{tabular}

\section{History}

The Syndrome of Klippel-Trenaunay (KTS) was already discovered and described by Isidore Geoffroy Saint-Hilaire in $1832^{1,2}$, a French Zoologue and teacher of Compared Anatomy, who studied the monstrosities in depth and was the founder of Teratology (the Science of monsters). He described a patient with concurrence of osteo-muscular hypertrophy and cutaneous vascular anomalies of the extremity. In the ensuing years other authors have described patients presenting with similar signs which included limb overgrowth and associated vascular anomalies.
In 1858, Adams published the first report in English language, where the author described a patient as "singular case of hypertrophy of the right lower extremity with superficial cutaneous nevus of the same side" ${ }^{3}$. This was followed by Trélat et al. ${ }^{4}$ who published in 1869 a summary of 12 case reports of patients with the concurrence of osteomuscular hypertrophy with unilateral cutaneous vascular nevus and varicose veins.

However, it was not until 1900's when two French physicians, Drs. Maurice Klippel and Paul Trenaunay, first recognized above mentioned concurrence of clinical findings as a separate clinical entity which they named "naevus variqueux osteohypertrophique" ${ }^{5}$ when describing two patients with cutaneous vascular lesions of the skin that were associated with asymmetric soft tissue and bone hypertrophy, what is today known as Klippel-Trenaunay Syndrome (KTS).

In the following years various authors have proposed different definitions for this clinical entity. Most notably, in 1907 Parkes-Weber described a similar case that differed from KTS in the presence of arteriovenous malformations ${ }^{6}$. Unfortunately, subsequently several authors merged the two disorders together as the Klippel-Trenaunay-Weber Syndrome, which caused confusion that persisted through the $20^{\text {th }}$ century with regards to classification and terminology, of these two distinctly different clinical entities. Today it is well established that KTS should be clearly distinguished from Parkes-Weber Syndrome (PWS) which is a high-flow vascular malformation characterized by arterio-venous shunting. Clinically this is of a paramount importance as clinical features, management and prognosis of these two syndromes are distinctly different.

KTS represents a complex congenital vascular disorder characterized by the pathognomonic triad of findings that include capillary malformation(s) (CMs), venous malformation(s) (VMs), and hypertrophy of affected extremity, with or without presence of lymphatic malformations(s) (LMs). (Figure 2) Congenital vascular malformation(s) (CVMs) associated with KTS patients are localized or diffused abnormalities in vasculogenesis and angiogenesis that arise by embryologic dysmorphogenesis without increased endothelial proliferation that causes true structural and/or functional anomalies of the vascular system $^{7,8}$.

These anomalies in turn can lead to variable clinical presentation and course (in both their extent and severity) what depends upon location, size and/or the type of vessel affected. Most frequently they cause discomfort, pain, hemorrhage, thrombosis, negatively affect patient's appearance, emotional well-being and can lead to a significant reduction in daily functional capacity and quality of life of patient. 


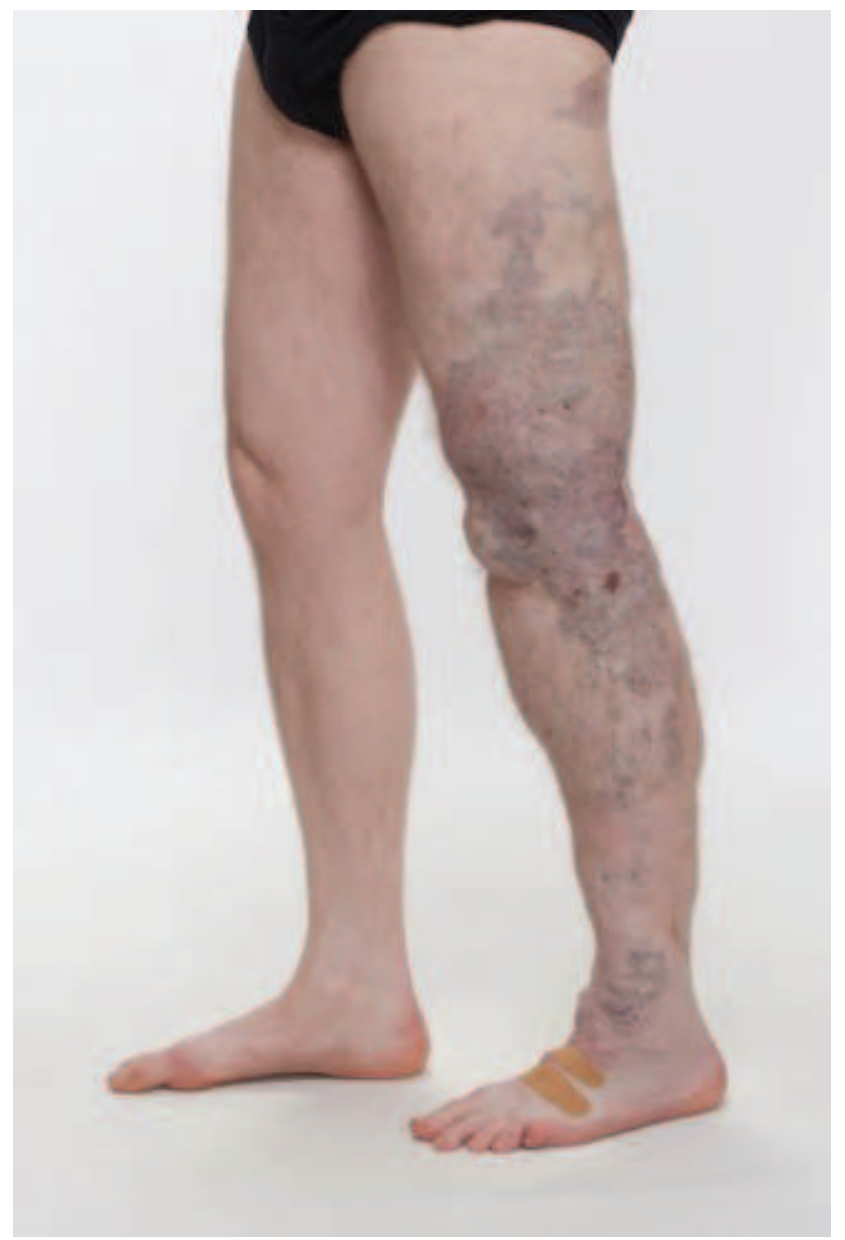

Figure 2 - A 32 year old KTS patient with pathognomonic triad of findings that include extremity hypertrophy, cutaneous capillary malformations and varicosities affecting the left lower extremity.

For most doctors - from primary care clinicians to subspecialists (including vascular surgeons and phlebologists) - management of KTS represents a difficult task and it is usually reserved for referral to specialized centers with expertise in this area.

Relatively low frequency at which KTS occurs, the confusing nomenclature which traditionally characterized majority of the early literature discussing KTS, overlap with other vascular malformation syndromes, such as PWS, Proteus Syndrome, and hemi-hypertrophy, as well as the absence of established guidelines for KTS management represents the main reason why expertise for diagnosis and treatment of KTS patients was most frequently centralized to major medical centers.

Consequently a significant number of KTS patients have been discouraged by the lack of correct diagnosis and proper treatment despite numerous visits to different clinics.

Relatively recently introduced concept of the multidisciplinary team approach, characterized by full integration of expertise of different medical specialists, combined with evaluation with modern diagnostic techniques and treatment with novel therapeutic modalities afforded the opportunity for the improvement in understanding of the pathophysiology and the management of KTS patients.

$\boldsymbol{B B}$ Lee reminded all the participants that such dedication for full three weeks ONLY for the KTS issues is virtually impossible other society/congress activity can afford! Indeed, "Vasculab is the first one ever as I know of willing to spare/dedicate full three weeks to its subscribers for free exchange of their opinion on the KTS as you always wanted to know but afraid to ask... So please take advantage on this unique opportunity Vasculab provides through full three week period unconditionally no other group ever did.", he declared.

BB Lee added the following remarks about the history of KTS in the $X X$ century.

"I feel obliged to clarify on the dark side of the CVMs through the last century. That is WRONG prejudice against the CVM as a whole with truly biased opinion based on many hearsays. Indeed, during my residency days in Medical College of Virginia in Richmond, Virginia in early '70, the CVMs- in those days we called it angiodysplasia!- were 'a curse to the surgeons' so that we were warned to stay out whenever possible.

My mentor, the late David Hume - who missed Nobel prize to receive for his pioneering work on kidney transplant together with Joseph Murray due to his early death by airplane accident - often quoted Dr. Emerick Szilagyi, condemning the CVMs as a sort of four letter words to the surgeons.

Dr. Szilagyi at Henry Ford Hospital, Detroit in '60, who is a legendary vascular surgeon with his tremendous work as a pioneer on the developments of vascular surgery combined with transplant surgery, became more famous with his incredible joke to his disciples to using the CVM cases as the tool to ruin- 'get rid of'- competing surgeon based on his horrible experiences with CVMS/AVMs.

Indeed, through the last century, a cavalier approach to CVMs, mostly led by surgeons alone, often resulted in disastrous outcomes with high recurrence and high complication/morbidity due to then limited knowledge and experiences in this unique vascular disorder. They simply learned that CVM is a unique vascular disorder of extreme variety with stigma of totally unpredictable behaviour. But then, they did not know it is due to its unique embryological characteristics.

Therefore, CVM remained most difficult and confusing diagnostic and therapeutic enigma through the century with a wide range of the clinical presentation; unpredictable clinical course; erratic response to the treatment with high recurrence; high morbidity of conventional treatment; confusing terminology without proper information on etiology, anatomy, and pathophysiology.

Such notorious reputation only added further confusion on the management of CVMs with erroneous prejudice as 'Enigma among the vascular disorders' (Edmondo Malan) ${ }^{9}$. And recurrence became the trademark of CVMs.

Through last three decades, we learned a lot through many painful lessons! Yes, it is still one of 'ultimate challenge to the clinicians' (Stephan Belov). But now we know how much we know and also how much we do NOT know on this unique embryological remnants. So we will be able to guide the colleagues through this mine field safely and further to teach how to defuse this mine: 'symbol of humiliation"'. 


\section{Etiology}

The Klippel-Trenaunay Syndrome represents a rare congenital vascular disorder without gender predilection that occurs with estimated incidence of approximately one in 100,000 live births ${ }^{10}$. Most KTS cases are sporadic without identified pattern of inheritance; however, several studies have reported familial occurrence ${ }^{7,11,12}$.Although the etiology of KTS still remains to be elucidated, data from molecular studies suggest that errors in embryonic development of the normal vasculature (which include angiogenesis, vasculogenesis and vascular remodeling) are responsible for development and progression of vascular malformations associated with $\mathrm{KTS}^{13}$.

In summary, this complex biochemical process is regulated by different vascular endothelial growth factors (VEGFs). By binding to receptor tyrosine kinases (VEGF-R1 and VEGF-R2) VEGF modulates endothelial proliferation and vessel tube formation ${ }^{14,15}$. This process is significantly influenced by an antagonist, angiopoietin-2. VEGF also stimulate angiogenesis with the action of angiopoietin-1 and its receptor (Tie2). Berry et al. suggested that in KTS there is an alteration in vascular remodeling, most likely at the level of altered angiopoietin-2 antagonism ${ }^{13}$. Early genetic studies also showed contradictory data. Although majority of the earlier studies reported KTS patients to have normal karyotype, there were studies that contradicted these findings ${ }^{8}$.

Specifically, Whelan et al. described a KTS patient who had a reciprocal translocation of chromosomes 5 and $11^{16}$. Chromosomal translocation was supported by Wang et al. who showed a balanced translocation involving chromosomes $8 \mathrm{q} 22.3$ and $14 \mathrm{q} 13^{17}$, as well as Timur et al. who reported a mosaic de novo supernumerary ring chromosome 18 in KTS patient18. Genetic susceptibility for capillary malformations, as one component of the clinical triad in KTS, was suggested by Eerola et al. ${ }^{19}$ Authors of this study identified a large genetic locus, $\mathrm{CMC}$, on chromosome $5 \mathrm{q}$ and by using genetic mapping identified heterozygous inactivating RASA1 mutations in families manifesting capillary malformations. However in 2013 Revencu et al. published opposite data showing that germline RASA1 mutations are not associated with $\mathrm{KTS}^{20}$.

More recent genetic studies suggest that underlying pathophysiologic mechanisms responsible for KTS development stem from mosaic activating mutations in the phosphatidylinositol 3-kinase catalytic (PIK3CA) gene and showed that several members of the PIK3/mTOR pathway have been implicated in the pathogenesis and progression of vascular anomalies ${ }^{21}$. Vascular endothelial growth factor (VEGF) is a key regulator in lymphangiogenesis and angiogenesis, and acts as both a potential upstream stimulator of, and a downstream effector in the mTOR signaling pathway ${ }^{22}$.

mTOR is the abbreviation term for 'mammalian target of rapamycin' and its inhibitor (mTOR-I) has been used extensively for decades as immunosuppressive drugs as 'sirolimus and everolimus' largely in renal transplantation. Indeed, sirolimus was the first mTOR-I approved for use in renal transplant and its activity is based on its binding ability to the immunophilin FK binding protein-12 (FKBP-12) to halt $\mathrm{T}$-cell progression from the $\mathrm{G} 1$ to the $\mathrm{S}$ phase(cell cycle) so that IL-2-induced protein synthesis and cellular proliferation can be inhibited.

But, lately mTOR-I was found to have antilymphangiogenic activity to induce the impairment on downstream signalling of vascular endothelial growth factor/VEGF-A through the inhibition of mTOR/p70S6K pathway in lymphatic endothelial cells (LECs). Further it was found to interfere with the intracellular pathway activation of LEC by VEGF-C, the main initiator of lymphangiogenesis ${ }^{23}$. In other words, mTOR inhibition impairs downstream signalling of VEGF-A as well as VEGF-C via mTOR to the p70S6 kinase in LECs. So, Rapamycin can inhibit VEGF-C driven proliferation and migration in concentrations as low as $1 \mathrm{ng} / \mathrm{ml}$.

In 2015, Luks et al. evaluated genetic aberration responsible for lymphatic pathogenesis in patients with lymphatic malformations $(n=17)$ and/or syndromes in which lymphatic malformation is present including patient with CLOVES $(\mathrm{n}=33)$, KTS $(\mathrm{n}=21)$ and FAVA (Fibro-Adipose Vascular Anomaly $\left.{ }^{24}\right)(n=8)$. Data from this study showed that somatic mosaic mutations in PIK3CA 25 genetic locus represent genetic mechanisms underlying development of the above mentioned syndromes. However, it remains to be elucidated why the same genetic PIK3CA gene mutation causes an isolated malformation in one patient and a different syndrome associated clinical presentation in another patient. One of the explanations can be based on the stage of the embryonic development when the genetic mutation arises as well as the location of the first mutated embryonic cell and the stem cells that arise from that particular cell linkage.

Mammalian target of rapamycin (mTOR) is a serine/ threonine kinase regulated by phosphoinositide-3-kinase (PI3K). mTOR acts as a master switch of numerous cellular processes, including cellular catabolism and anabolism, cell motility, angiogenesis, and cell growth and is becoming a target of relatively novel pharmaceutical agents being tested $^{26}$. In 2016, in a study funded by National Institute of Health, Dimopoulos et al. performed genotyping of DNA from 17 KTS patients by using microarrays ${ }^{27}$. 
Authors identified 15 copy number variants in genes involved in chromatin modification, which is a key regulatory process of embryonic vascular development. Specifically, authors identified deletion in two cases within transcripts of histone deacetylase (HDAC9), which is essential for angiogenic sprouting of endothelial cells. One case had duplication upstream of a transcription factor essential for embryonic development (SALL3 ${ }^{28}$ ), that inhibits DNA methyltransferase responsible for embryonic de novo DNA methylation (DNMT3A). Data of this study also showed that another patient had a duplication spanning ING5, a histone acetylation regulator which is active during embryogenesis. Although above referenced initial genetic data are promising, further studies (with ideally larger number of patients) are needed for the more accurate assessment of genetic aberrations responsible for pathogenesis of KTS. These findings have a potential to provide a fertile environment for development of novel genetic diagnostic, prognostic and therapeutic modalities.

\begin{tabular}{|c|c|}
\hline & Genetics \\
\hline CMC1 & large locus on chromosome $5 \mathrm{q}$ \\
\hline DNMT3A & DNA methyltransferase 3 alpha \\
\hline FKB9-12 & immunophilin FK binding protein-12 \\
\hline HDAC9 & histone deacetylase \\
\hline ING5 & histone acetylation regulator \\
\hline mTOR & mammalian target of rapamycin \\
\hline mTOR-I & $\begin{array}{l}\text { mTOR inhibitor drug, like sirolimus anc } \\
\text { everolimus }\end{array}$ \\
\hline $\mathrm{PI} 3 \mathrm{~K}$ & phosphoinositide-3-kinase \\
\hline PI3KCA & $\begin{array}{l}\text { phosphatidylinositol 3-kinase catalytic } \\
\text { PIK3CA }\end{array}$ \\
\hline RASA1 & p120-RasGTPase\#activating protein \\
\hline SALL3 & salt-like 3 DNMT3A inhibitor \\
\hline Tie2 & angiopoietin-1 and its receptor \\
\hline VEGF-R1 & $\begin{array}{l}\text { Vascular endothelial growth factor } \\
\text { receptor-1 }\end{array}$ \\
\hline VEGF-R2 & $\begin{array}{l}\text { Vascular endothelial growth factor } \\
\text { receptor- } 2\end{array}$ \\
\hline VEGFs & Vascular endothelial growth factors \\
\hline Table II - Ge & \\
\hline
\end{tabular}

\section{Discussion}

$\boldsymbol{B B}$ Lee affirmed that marginal vein $(M V)$ maintains embryonic venous structure with the lack of media, NO SMOOTH MUSCLE LAYER, besides NO VEIN VALVES!

According to NF Liu, lymphatic malformation is a common component, but have been underreported in many studies, in part because of difficulties in establishing a suitable proof of lymphatic involvement of KTS. It is not possible to directly observe the abnormal development of the lymphatic system in KTS patients until we have used the MR lymphangiography ${ }^{29}$.
Not only lymphatic vessel is involved in KTS, the inguinal lymph node may also affected (including lymph node aplasia, hypoplasia or hyperplasia). Venous system and lymphatic system have close relationship during embryonic development, it may explain in part for the co-existence of the pathology of both systems in the disease. Recent studies have showed that genes that regulate development of venous system as VEGFs, Angiopoietins..., also show important effect on lymphatic development. These study may explain the clinic phenotype of co-involvement of the two system in KTS and primary lymphedema, added NF Liu.

But are those veins really dysplastic following the histological definition of dysplasia? Is there cytological atypia in biopsy samples with atypical nuclei $O R$ are we looking at architectural abnormality which is not dysplasia? (asked K Parsi)

BB Lee noted that histology says simply they are "dysplastic veins", but he was not very convinced about the usefulness of that data to define KTS.

The cause of Klippel Trenaunay syndrome is a cellular mosaicism. This mosaicism may be present in every cell or group of cells, argued M Vaghi.

$\boldsymbol{B B}$ Lee remarked that in regard to the discrepancy between the LSG and ICG lymphangiography the lymphatic defects involved to KTS are closely linked to coexisting VM (rather than co-developed!) as a typical 'mosaic pattern' (as already noted by $M$ Vaghi) so that its truncular form/primary lymphedema looks a lot different from independent lesion, BB Lee added. As NF Liu pointed out, MR Lymphangiography shows its dysplastic development as aplasial hypoplasia/hyperplasia is only a part of it along the collecting system but we do see many defects involved to lymph nodes. So BB Lee concurred with what Cristobal Papendieck claims as three separate groups to 'lymphangiodysplasia/ lymphnododysplasia/ lymphangioadeno-dysplasia'.

We speculate this unique condition named as KTS as the outcome of multiple genetic mutations affecting not only vascular but also other organs/systems/tissues of mesodermal origin in particular, most probably as a 'mosaic' pattern. So musculoskeletal overgrowth remains to be assessed from this genetic mutation point of view as we previously pointed out. Indeed, so far up to Year 2015, we do NOT have any other clue and the VM as the culprit to cause abnormal long bone growth together with LM for KTS cases remained to be verified for this genetic mutation involved. In other words, there is no specific confirmed gene mutation identified yet for KTS altogether. So regretfully we do NOT have clear answer on "different therapeutic implications" and "Why some patients present with limb length and size overgrowth and others no if they all have VM and $L M^{\prime \prime}$, insisted BB Lee.

Nevertheless, a limb length discrepancy is one of secondary phenomena caused by the primary CVM lesion in its majority, we speculate the venous hypertension caused by (extratruncular) VM lesions along the epiphyseal plate as a major culprit of angio-osteohypertrophy. And when the VM, either extratruncular or truncular, is intervened on time, such progress of abnormal long bone growth can be arrested/corrected, pointed out BB Lee.

WL Olszewski underlined the important point of aplasia of lymphatics and nodes. So far nobody proved and reported objective data on selected (from other coexisting developmental defects) lymphatic aplasia. The 1962 Kinmonths concept of aplasia based on unsuccessful lymphatic cannulation for lymphography is not more tenable, as biopsies showed normal lymphatic wall layers with lumen full of acellular amyloid-like masses. In the so called KTS he found normal collectors on lymphography, on ICG thousands of fluid lakes and on histology thousands of minute fluid cysts. Not to describe now 
the coexisting deformed blood vascular structure. Fluid lakes have no connection with collecting trunks."

C Recek added several intriguing questions: "The limb overgrowth in KTS is really the consequence of hemolymphatic malformation, how does that come about? Is there at all any causal relationship between the hemolymphatic malformation and the soft tissue and bone hypertrophy? Or are both released by unknown factors, e.g. epigenetically activated or suppressed genes? Anyway, the relationship between vascular malformations and congenital vascular bone syndrome (VBS) remains obscure. So, the enigma continues." In addition, he stated that it was not specified how the hemodynamic disturbance in KTS looks like.

BB Lee answered that we only speculate the etio-pathogenesis of VBS and describe vaguely as the result of the stimulation to epiphyseal plate by the VMs nearby before the plate is closed. But we know the overgrowth of bones and soft tissues as well are closely related from changes in one or more genes that regulate the growth of blood vessels during embryonic development though no associated genes have been identified. Nevertheless, all the conditions of KTS we know of are almost always as the outcome of gene mutations that are not inherited, and all these so called 'somatic mutations' present only in certain cells - so far no associated genes have been found -, probably occurring very early in development, and explain why the conditions of KTS are often limited to specific areas of the body. Indeed, as you previously touched briefly, the final answer on this mixed condition of defective genes is the severity of 'mosaicism'- otherwise, embryo would not remain viable as a homozygous zygote.

\section{Classification}

As mentioned earlier, historically numerous attempts have been made to properly classify congenital vascular malformations based on anatomic, clinical, and/or embryologic criteria and no real consensus existed regarding nomenclature and management of these lesions ${ }^{30,31}$. Based on a classification of "vascular birthmarks", initially proposed by Mulliken and Glowacki in $1982^{32}$ the International Society for the Study of Vascular Anomalies (ISSVA) introduced a classification system in which all vascular anomalies were divided into two categories: vascular malformations and vascular tumors. The differentiation of vascular anomalies into tumors and malformations permitted more effective communication between different medical specialists.

Unfortunately, the eponym based terminology which characterized the ISSVA classification, as well as the lack of clinical applicability of this classification with regards to pretreatment planning, was believed by many to be the major limitation for widespread acceptance and utilization of this system. To address ISSVA classification limitations the authors of "Hamburg" and subsequently "Modified Hamburg Classification" developed a classification system by incorporating malformation flow characteristics (i.e. arterial, venous, capillary).

In addition, they defined vascular malformation based on the stage of developmental arrest during embryogenesis into truncular and extratruncular lesions which is important for treatment selection and prognosis of treatment outcomes as extratruncular lesions are associated with significantly higher recurrence rates and resistance to therapy, presumably because of their preserved mesenchymal characteristics of independent growth potential ${ }^{33}$. "Modified Hamburg Classification" system has been considered to be "a more clinician-friendly classification for vascular malformation management" as outlined in the 2009 Consensus Document for the treatment of venous malformations of the International Union of Phlebology (IUP) ${ }^{34}$. According to this classification KTS is a low flow vascular malformation, as it does not have an arterial component.

\section{Discussion}

\section{The KTS Eponym}

R Mattassi noted that Edmondo Malan from Italy, considered internationally one of the main pioneers in CVM, in 1974 reported about 460 cases of CVM (one of the main series of cases at that time). In his book ${ }^{9}$ he wrote "the Klippel-Trenaunay-Parkes-Weber eponym is meaningless and should be abandoned". That because he found in the literature much confusion about.

Stefan Belov, another pioneer in CVM, described 11 different types of CVMs with the well-known triad of signs in cases defined as KTS. Also he was of the opinion that KTS is a confusing term to be avoided, because the same clinical picture may be originated by different malformations.

However, the use of KTS diagnosis is so diffuse that it is better to maintain it, just avoiding its incorrect use. That was done partially during the VM international consensus for IUP (Int Angiol, 2014) ${ }^{31}$.

The intention of the KTrenaunay Debate was to improve the definition, maintaining the KTS eponym, as abolishing it seems impossible. KTS should only be used correctly and not as a general term for anomalous vessels, he concluded.

However, the eponym can have also advantages, as the description terms do not include all localizations and may not highlight complications in liver, lung and brain, noted M Vaghi. In addition, in Italy you can have some economical support for people affected by congenital vascular diseases, all classified with eponyms. Changing the nomenclature will automatically exclude these patients from the financial support, he added.

On the contrary in the USA, improper use of the term KTS would make the clinician legally liable, so that we urge the colleagues to use the term carefully especially on clinical document/ record, argued BB Lee, saying that they effectively replaced/renamed KTS to Hemolymphatic malformation (HLM) based on Hamburg Classification.

The difficulty of the matter is amplified by previous clinical nosographic classifications as Klippel-Trenaunay-Weber syndrome (KTW) or Parkes-Weber (PW) which are only the emerged part of the iceberg that the modern imaging is today showing. Maybe we should better retain the eponyms only for the history of medicine, noted $\mathbf{C}$ Franceschi.

BB Lee declared that he feels ISSVA led/opened Pandora's box! He was NOT talking about many legitimate syndromes like CLOVES syndrome which represents each components (congenital lipomatous overgrowth, vascular malformation, epidermal nevus, scoliosis), but 
he was talking about illegitimate(?) NAME-based syndrome which represents NOTHING but the lists of the names of the person who documented first.

\section{Definition}

One of the main issues in the discussion was the identification of the primary and secondary defects in KTS, in order to achieve a better definition.

BB Lee reminded that AVMs are absent in KTS and can be found only in PWS instead.

R Mattassi reported about a recent ongoing statistic (46 cases, Castellanza, 2011 - 2015, later published on Phlebolymphology ${ }^{35}$ ), where all cases were studied with modern technology (Duplex scan, MRI, Lymphoscintigraphy). While only superficial dysplastic veins were present in all cases, other signs and vascular defects occurred in a lesser extent.

JN Markovic affirmed that giving a clear definition of KTS is a critical initial step. In his opinion, the definition should be based on clinical applicability and preservation of original findings described by M Klippel and P Trenaunay, allowing a certain degree of deviation.

As regards the clinical applicability, emerging novel therapeutics with preliminary data show that mTOR-I are effective in the treatment of pediatric patients only in KTS patients with LM component. Therefore, classifying a patient as KTS with OR without LM is clinically relevant, especially with regards to treatment planning.

The exclusion of the osteomuscular discrepancy from KTS definition could carry the risk of contradicting findings of the original authors and silencing the previous work that steamed from their discovery. He suggested the definition to incorporate osteomuscular discrepancy as a pathognomonic symptom and low flow hemodynamic characteristics $(\mathrm{VM} / \mathrm{CM}+/-\mathrm{LM})$ as chief symptom. In his opinion deep venous system status should be incorporated in diagnostic work up of KTS rather than in the definition.

BB Lee added that LM is a possible component of KTS. That means we should not talk about KTS + LM but simply of KTS. As a part of primary criteria, he suggested to consider the fact that (anterior) lateral embryonic/marginal vein (MV) is ONE of unique truncular VMs as an embryonic tissue remnant which is supposed to be involute/ regressed on the birth, but remained through due to arrested/defective development in its later stage of embryogenesis to form the venous trunk.

Naturally there are other risks of truncular VMs directly involved to the (named) venous trunk like iliac vein aplasia/absence or femoral vein hypoplasia, either as an independent VM lesion if not combined with MV ( in our series, over 25 to $30 \%$ were identified for 'coexisting iliac/femoral/ popliteal vein dysplasia).

For secondary criteria, he stated that in his personal perception it is hard to imagine KTS with NO port wine stain ( Maurice Klippel included this as a triad, while LM which was added later by Paul Trenaunay). Hence, he once defined this unique group of VM + $\mathrm{LM}$ and no CM as 'veno-lymphatic malformation (VLM)' as per recommendation by his mentor, Leonel Villavicencio. But in order NOT to add more confusion, he stopped using this new term of VLM for more than a decade. So his personal feeling was we should stick to the original claim led by the late Stefan Belov of Bulgaria with all three components as mandatory CVM components of KTS.

F Passariello noted that using simply a description instead of using an eponym could be considered a solution, though it does not comply with the difficult and variable clinical picture of the syndrome.
Furthermore, a good classification should be also extendible to the future. For instance, the original KTS definition by Klippel was later extended adding the lymphatic component. On the contrary, specifying in details the components in the definition blocks definitely any further improvement.

R Mattassi pointed out the question if limb overgrowth should be mandatory for KTS. Several patients have bilateral disease and combination of two or more vascular defects, but no limb length discrepancy. How to define them? Another point regarding limb shortening. Are these cases KTS or not? Some authors call them Servelle-Martorel syndrome. He declared that CM is not a mandatory requirement and certainly in his current paediatric list, $\mathrm{CM}$ is seen in less than $30 \%$.

K Parsi intervened saying that what we really have to be careful about is having a circular argument. In other words, if some patients were excluded to start with due to the wrong definition, then all statistics will be wrong as the definition was wrong in the first place: in simple words, using a criterion to assess the diagnosis and then finding that item present in $100 \%$ of your sample.

This especially applies to dysplastic veins and limb length hypertrophy. He remarked that this needs to be put in the context, because in his paediatric population he observed that early intervention can slow down the growth. So, while limb hyperplasia should be considered a criteria, it is a dynamic concept and needs a further definition.

F Passariello observed that nowadays we have the old completely clinical KTS classification and the new diagnostic facilities, which recognize the presence of single components and needs sophisticated instrumental tools to assess (for instance deep veins occlusion/dysplasia) or exclude the components (for instance AV fistulas, which change the diagnosis towards Parke-Weber Syndrome).

The two approaches are completely different and no problem arises if we try to use them separately, while the problem arises in the attempt of calling KTS (old eponym) something which is investigated in each component, using modern tools.

I Baumgartner remarked that we need a clear definition, declaring that she does not treat the KTS, but individual problems existing in an individual patient so that the sophisticated semantic definition becomes less important. Open question for her is if LM is mandatory or NOT to define classical, complete KTS.

R Mattassi noted that the extension of the defect is important. KTS exist only if the whole limb is involved. CVM of just a limited part of the limb (foot, calf, thigh) is not KTS.

Anyway, the term/condition of KTS can be applied to any limb, upper or lower or both! "Involvement of other organs/systems is another issue for KTS!", argued BB Lee. Indeed, the vascular malformation can develop anywhere throughout the body where the arterial-venouslymphatic circulations reach. Lower gastro-intestinal (GI) bleeding is one of the most common GI complications caused by the VM involved to the colon-rectum among KTS patients, and 'lymphorrhea' including 'chyloreflux' is also a common complication of the LM involved to KTS, with GI as well as gastro-urinary (GU) localizations ${ }^{36,37}$.

The most notorious findings are the 'vascular bone syndrome'/ angio-osteodystrophy, secondary to $\mathrm{VM}+/$-LM, GI bleeding secondary to VM and lymphorrhea and chyloreflux by LM. Regarding KTS and chylous reflux, this type of association is infrequent, while milky lymphorrhea can be found in Waldmann's disease, added MA Amore.

R Mattassi expressed the opinion that these locations without limb involvement cannot be defined KTS. Reason is that definition 
of vascular defects is not possible like in the limbs: how can we establish truncular defects in an infiltrating VM or LM of the cheek or of the thorax wall? How can we find truncular LM in that defects? He proposed to exclude from the definition of KTS vascular defects of other parts of the body, without limb involvement.

\section{Definition attempts}

K Parsi proposed an interesting classification, based on primary and secondary criteria, as follows.

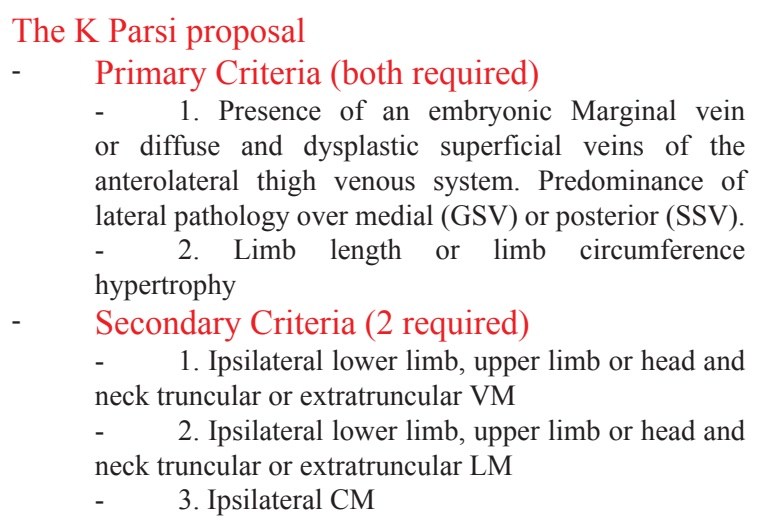

The primary and secondary components approach is nowadays common to several disciplines and the first similar classification dates to 1958 with the classification of rheumatoid arthritis from the American Rheumatic Association, based in the origin on 10 items, noted $\mathbf{F}$ Passariello. According to his opinion, the classification proposed by K Parsi was very interesting, but the criterion used to arrive to this discriminating tool was not declared.

M Vaghi proposed to define KTS as "truncular congenital venous anomalies associated with limb overgrowth". Other features like naevus, lymphatic disease may be added to the original nucleus. Given the complete classical picture (naevus, limb overgrowth, dilated veins), I Baumgartner added a rational scheme for classification as follows.

\section{The I Baumgartner proposal}

KTS (complete classical picture; LM?)

- $\quad$ give involvement and main problem for patient diffuse, dysplastic superficial veins, naevus, limb hypertrophy, III (? LM needed to define complete classical picture?)

large marginal vein with localized intravascular coagulation (LIC) and orthostatic symptoms, aplasia of femoral vein painful pelvic manifestation of $\mathrm{VM}$ mild, clinically latent LM (stage I) naevus (non disturbing) limb length difference $(<2 \mathrm{~cm})$

\section{- Incomplete KTS}

give involvement and main problem for patient But absence of one sign of the triad But absence of LM

No KTS / diagnosis is VM or LM

VM - patients with a single type of VM (truncular defect, like $M V$ or deep vein anomaly or extratruncular forms) alone. As these cases do not meet the mandate of "syndrome" they should not be defined as KTS

$\mathrm{VM} \& \mathrm{CM}$ - patients with a single type of VM and naevus without limb overgrowth and LM

LM \& CM - patients with a single type of LM and with naves but no VM.
R Mattassi stated that KTS is a Syndrome (combination of defects, not a single one!) and with diffuse, dysplastic superficial veins + other defects. In addition, he provided an exclusion criterion, as follows.

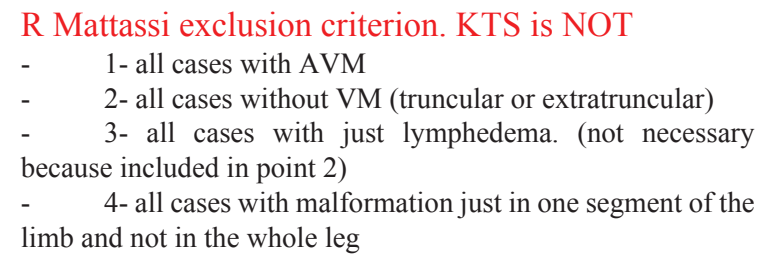

F Passariello suggested to try a description based on something similar to the CLOVES description, based on the following items: (C)ongenital, (L)ipomatous, (O)vergrowth, (V)ascular malformation, (E)pidermal nevus, (S)coliosis. If better adapted to CVM, it could describe all the component combinations, without any need to rely to the old KTS eponym.

BB Lee intervened saying that it would be the most ideal way to describe KTS. Indeed, the IUP tried to organize it when starting the first VM Consensus in $2009^{34}$ using the CLOVES Syndrome, though this fruitful way was later abandoned.

He underlined the need of classifying KTS as a Hemolymphatic Malformation (HLM) by Hamburg Classification, proposing the following definition: "KTS is a combination of truncular and extratruncular VM and LM which may originate secondary effects".

Possible vascular defects are 4: truncular and extratruncular venous and truncular and extratruncular lymphatic. A fifth defect can be added which is capillary malformation (CM) or cutaneous nevus flammeous.

Secondary lesions/conditions (e.g. leg length discrepancy; chyluria; hematochezia; pulmonary embolisms, etc.) can be present. Limb length discrepancy can be overgrowth or limb shortening. However, secondary effects are only the result of the vascular defect: there is no limb overgrowing without vascular defect. That means that the crucial point is the vascular defect and not the secondary effect. In his opinion, as limb length discrepancy is secondary and may not be present, it should not be included in the definition.

JN Markovic noted that at his Institution they define KTS as "Low Flow Vascular Malformation (VM/ CM +/- LM) + osteomuscular discrepancy". Defining KTS just as "combination of truncular and extratruncular VM and LM, with requirement that the existence of two of the above mentioned malformations are enough for definition of KTS, allows to define erroneously the combined extratruncular VM + extratruncular LM as KTS. These patients can be simply classified as combined CVM instead.

Furthermore, the definition of KTS as "combination of truncular and extratruncular VM and LM" is excellent, but it should be added "in patients with osteomuscular hypertrophy", he argued. In absence of hypertrophy, he would classify those patients as "Combined CVMs" instead, as proposed in IUP 2014. It should also be emphasized that we are not referring just to length discrepancy but also to circumference/ osteomuscular hypertrophy.

\section{Clinical Presentation}

Presentation of patients with KTS can range in severity from trivial, mild forms such as capillary malformations and few veracities of the affected extremity causing only cosmetic concern to life- 
threatening, severe disability associated with massive limb overgrowths, chronic pain, infections, thromboembolism and/or hemorrhage from venous malformations ${ }^{38-40}$. As mentioned in the introduction, the classic triad of KTS findings include capillary malformation, venous malformation, and/or soft tissue or bony hypertrophy of affected extremity. In a significant number of KTS abnormalities of the lymphatic system are present either in form of primary lymphedema, cutaneous vesicles draining lymph fluid, cystic hygromas or lymphangiectasia associated with reflux of the chyle ${ }^{41}$.

Patients with at least two of the three classic findings have been classified as incomplete KTS form ${ }^{42}$. Less frequently, a shorter and smaller limb may be present instead of hypertrophic extremity. With few exceptions, most frequently the presence of physical exam findings of the baby after birth will persist and will define the appearance of a patient. Some of the findings can worsen with triggering factors such are infection, injury, influence of hormones during pregnancy or puberty. Occasionally symptoms can worsen without identifying triggering factor.

A study from Mayo Clinic, that evaluated 252 KTS patients, showed that the capillary malformations, tissue or osteo-hypertrophy and varicosities or venous malformations were present in 246 (98\%), 236 (94\%) and $182(72 \%)$ patients, respectively ${ }^{43}$. More frequently the lower extremity was involved (70\%) and the malformation was unilateral in $81 \%$ of cases. Data from this study also showed that most common presenting symptoms included swelling (70\%), hemorrhage (17\%) and pain (7\%). $15 \%$ of patients had a history of superficial phlebitis. $4 \%$ of patients had a history of deep vein thrombosis and the same percentage had pulmonary embolism. One pulmonary embolism was lethal. Lateral varicose veins, medial varicosities and suprapubic varicosities (due to iliac vein aplasia) were found in $56 \%, 19 \%$ and $1 \%$ of patients, respectively.

Presence of the lateral embryonic vein deserves special consideration since the hemodynamic alterations associated with blood stasis in these frequently valveless veins not only causes symptoms but is also associated with a high risk of venous thromboembolic events ${ }^{44}$. It has to be emphasized that there is inconsistent terminology that characterizes majority of the literature discussing persistent embryonic veins. The persistent lateral (marginal) embryonic vein and the persistent sciatic vein are the only two persistent embryonic veins found in KTS patients. The lateral marginal vein is a superficial vein although from the anatomical stand point the term "superficial" is a misnomer since this vein frequently penetrates the deep fascia and involves muscles of the deep compartment of the lower extremity. Persistent sciatic vein is part of the deep venous system.

\section{Diagnostic Imaging}

Historically, the diagnosis and treatment of KTS have been hampered not only by the complex nature of these vascular lesions, but also by the absence of defined imaging protocols and therapeutic algorithms. Multiple diagnostic modalities are used (alone or combined) to evaluate KTS and to confirm the initial clinical diagnosis including US imaging, CT scan, catheter based angiography, and $\mathrm{MRI}^{45-47}$.

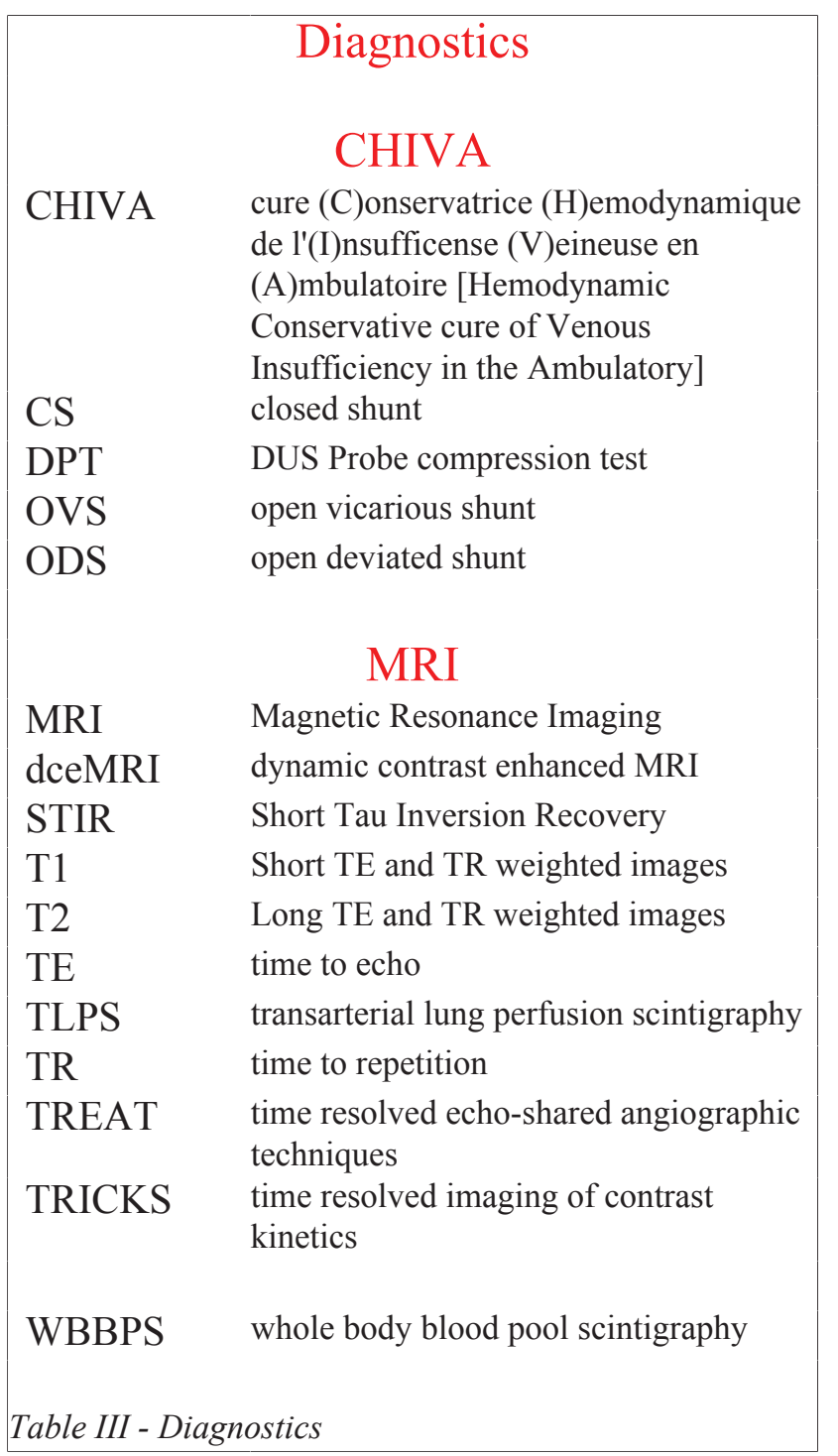

\section{Ultrasound}

Physical examination is most frequently followed by detailed color duplex ultrasonography of the venous system of the leg. Ultrasonography is frequently utilized as it is non-invasive, widely available (including non-hospital settings) and inexpensive. Ultrasonographic evaluation is utilized to establish patency and to evaluate for any anomalies, including hypoplasia, aplasia and/or aneurysms of the deep venous system. Complete ultrasonographic evaluation needs also to include assessment for deep venous thrombosis and competence of deep, superficial and perforating venous systems. In addition to this, complete evaluation of lateral marginal vein is 
performed as well. On duplex ultrasonography venous malformations demonstrate monophasic, biphasic and no detectable flow in $78 \%, 6 \%$ and $16 \%$ of cases, respectively ${ }^{48}$.

Since the '90s, an increasing interest is seen towards the so called hemodynamic approach to vascular malformations, especially to KTS. This approach is derived from the CHIVA strategy for the treatment of chronic venous insufficiency. The French acronym CHIVA means cure Conservatrice Hemodynamique de l'Insufficense Veineuse en Ambulatoire ${ }^{49}$ [Hemodynamic Conservative cure of Venous Insufficiency in the Ambulatory]. As CHIVA was treated extensively during the Debate, we will present it here its specialized ultrasound assessment.

\section{The modified Perthes test}

The deep veins occlusion/hypoplasia/agenesia (often femoral) and the superficial atypical venous conduct called Marginal Vein (MV) are two important components of the venous Malformation (VM) in KTS, though sometimes they can be absent.

The MV is an anatomic anomaly with variable functional impairments. This vein is sometimes totally or partially compensating a deep vein obstacle (open vicarious shunt or OVS), sometimes fed and overloaded totally or partially during the diastole by the deep veins (closed shunt or CS), sometimes a combination of both. In all the cases, the associated $\mathrm{CM}$ is aggravated by or totally due to the increased venous pressure due to the shunts and the residual pressure at its level is high, cause of the low resistance of its microcirculation ${ }^{50-53}$. A detailed venous mapping is required, with the detection of the systolic and diastolic reflux.

The role of MV can be contextualized by the study of the SystoDiastolic reflux in the short saphenous vein (SSV) and MV (systolic and diastolic ultrasound venous carthography). A "Modified Perthes Test" can help in the selection of the patients and of the sites of surgical intervention. The test, proposed by $\mathrm{C}$ Franceschi ${ }^{54}$, checks the delayed response of the limb exposed to a long lasting exclusion of the superficial network (including MV). The test can be achieved also by an eccentric compression, just limited to the $\mathrm{MV}^{55}$ and is useful in the selection of the patients for surgery and in the choice of the possible sites of surgical intervention.

N Morrison proposed a prolonged Perthes test with an associated huge effort (presented during the systo-diastolic event and also later on Vasculab ${ }^{56}$ ). However, during a hard exercise, after a few calf contraction there will be no additional appreciable ejection of blood. This fact can be easily seen in air plethysmography, where (whatever the manoeuvre) the leg volume reaches almost a plateau after a few repetitions. In other words, muscles during the exercise do not receive and do not expel much blood, like they were in anaerobe metabolism.

In addition, while the Morrison manoeuvre testifies the patency of the deep system, nevertheless if compared to the other variants of the manoeuvre it points only approximatively to the punctual sites for the MV interruption.

Recently, C Franceschi proposed a very promising variation of the Perthes test, the DUS probe compression test (DPT) ${ }^{57}$ (KTrenaunay msg $11186^{58}$ ), achieving the same results of the modified Perthes test, but using a very quick procedure. The test has the aim of assessing a compensating vein, whether a varicose or a malformed vein, and is based on the compression by the ultrasound probe below a perforating vein, during the activation of the venous pump.

\author{
DUS probe compression test (DPT) \\ The result can be \\ a venous collapse in case of closed shunt (open \\ deviated shunt or ODS) \\ an unchanged calibre in case of deep venous \\ incompetence (deep competitive reflux) \\ an increase of the tension of the venous wall in \\ case of flow compensating a deep obstacle
}

The modified Perthes test (any of the above cited) can be effected before conservative procedures, showing to the surgeon (as well as to the patient) what can be expected from the disconnection at the compressed point.

In order to test the outflow capacity of the deep venous system, C Recek proposed to use the occlusive plethysmography, performed firstly with open MV and later with the compression of the MV (with a tourniquet or digitally) to assess how much it contributes to the outflow. The occlusive plethysmography is used in analogy to the work of Trendelenburg, who tested the patency and outflow capacity of deep veins in varicose vein patients using his reversed Trendelenburg test.

In the standing position, a tourniquet was placed in the thigh to compress the incompetent GSV. Then the patient laid down and elevated the limb. Varicose veins emptied through calf perforators and deep venous system, also not as quickly as through the incompetent GSV after releasing the tourniquet, Trendelenburg wrote. He insisted that both the normal test and the reversed one should be performed before ligation of the GSV. The same can be applied to the MV in KTS.

These investigations are not theoretical, because they help in understanding in a rational way "if" and "in which extent" the MV can be excised and in addition "how to deal with the naevus" and "if and where" to operate.

\section{Other diagnostic Imaging}

Plain X-rays of the bones (scanograms) are used as a routine radiologic test in patients with limb size discrepancy. X-rays are performed to measure bone length. Occasionally they will demonstrate phleboliths as well. Contrast-enhanced CT can identify the location of the venous malformation, bony involvement, vessel ectasia, and aneurysm formation $^{59}$. True extent of the lesion into soft tissue, however, is underestimated as only contrast-enhanced vessels opacity. Although still frequently used US and CT scan provide variable degrees of diagnostic accuracy or frequently insufficient information with regards to pre-procedural planning. This is especially true for medical centers where treating physician does not perform diagnostic ultrasonography, as this evaluation is performed by a designated ultrasonographer.

Given the above mentioned limitations MRI became the imaging modality of choice in the evaluation of KTS in specialized centers. MRI gives a bright signal on T2-weighted spin-echo sequences for the parenchymal portions of vascular lesions which is not only useful to delineate the extent of the malformation throughout the involved tissues but it also allows for treatment planning and can be used for objective assessment of the treatment efficacy ${ }^{60}$. Full extent of tissue involvement is readily depicted when T1 and T2 or Short Tau Inversion Recovery (STIR) images are acquired.

Venous malformations associated with KTS have characteristically augmented intraluminal signal on T2-weighted images. There is frequently an intraluminal signal on the T1-weighted images as well. Low flow vascular lesions enhance with contrast and normally do not contain flow voids. If present, macrocystic lymphatic malformations are often differentiated from venous malformations by their predominantly cavitary, lobulated and septated appearance that is 
characterized by hypointense signal on T1-weighted and hyperintense signal on T2-weighted and STIR images.

Distinct from venous malformations, macrocystic lesions do not enhance with an exception of "rings and arcs" appearance within cyst wall or septae. Macrocystic lesions are more likely to demonstrate fluidfluid levels. Microcystic lesions are differentiated from macrocystic lesions by the absence of dominant cystic spaces and lack of contrast enhancement and this is used as criteria to differentiate them from venous malformations. High-flow vascular malformations typically do contain flow voids that can be identified on T1- and T2-weighted images.

This radiologic characteristic is used for excluding arterial flow, which is found in PWS. Conventional MRI was not used only for evaluation of a lesion but for the evaluation of deep venous system. This is very important as the prevalence of deep venous system anomalies is high in KTS patients and the status of deep venous system and its relation to the vasculature is used for treatment planning.

Although conventional MRI shows the lesion's flow characteristics, relation to normal circulation and provides good soft tissue definition it is frequently not adequate to provide hemodynamic data. In addition, many particulars can mitigate conventional MRI findings; for example: a blood vessel that courses within an imaging plane may produce an intraluminal signal despite fairly fast flow, falsely suggesting a low-flow malformation which can potentially lead to catastrophic side effects if the lesion is treated as low flow malformation. To avoid this, relatively recently dynamic contrast enhanced MRI (dceMRI) started to be increasingly used in highly specialized referral medical centers ${ }^{61}$.

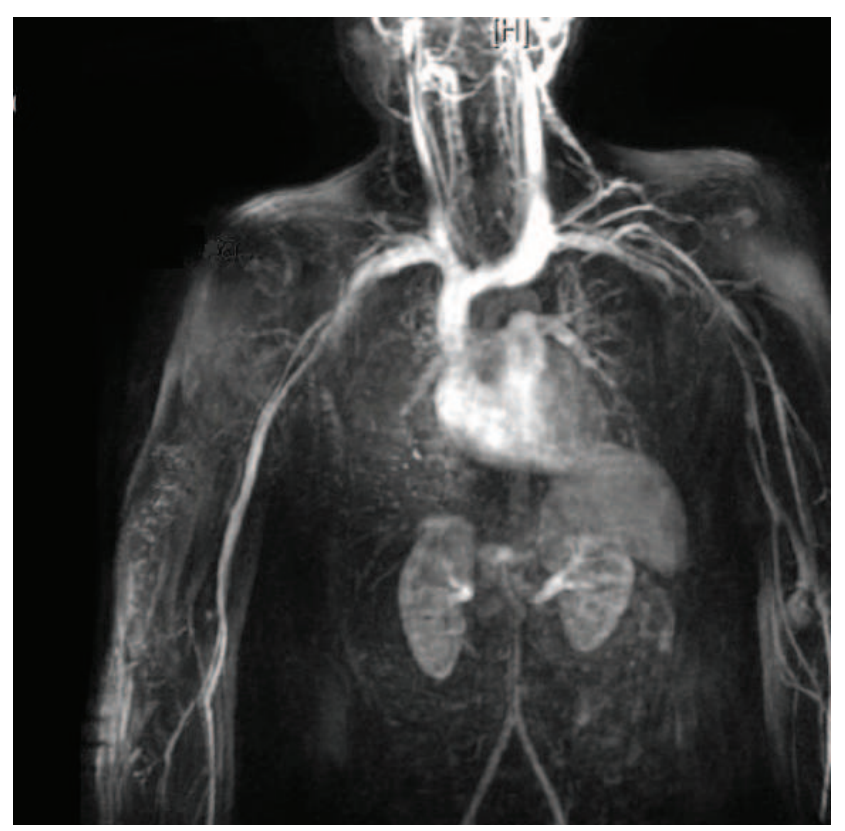

Figure 3 - dceMRI of the right upper extremity demonstrates absence of the appearance of the malformation during the arterial phase of the maximum intensity projection time-resolved imaging, which is confirmatory to exclude arterio-venous shunting. This is a critical step for treatment planning.

dceMRI can be used to more accurately assess flow within the lesion since it yields more information with regards to hemodynamic characteristics by utilizing time resolved imaging of contrast kinetics (TRICKS) and time resolved echo-shared angiographic techniques (TREAT) where images are acquired sequentially ${ }^{63,64}$. This dynamic image acquisition produces multiple image volume sets, each at a different time points that are subsequently converted to a maximumintensity projection, which are displayed in a way that vessel and lesion enhancement are the only structures visualized.

This technique generates the appearance of dceMRI images that are analogous to a display of a conventional digital arteriogram with background subtraction. (Figure 3) In this way, main vascular components of the lesion are enhanced, which provides better definition and more accurate differentiation between high-flow and low-flow lesions than conventional MRI. In addition, dceMRI has the advantage of being able to detect dominant or multiple feeding vessels, what is critical for treatment planning.

Image acquisition extends from the arterial to the late venous phase using time-resolved imaging of contrast kinetics, time-resolved echo-shared angiographic technique, or time-resolved angiography with stochastic trajectories dynamic sequences. Besides defining the extent of the abnormality, dceMRI results interpretations includes information with regards to the type of vascular malformation as well as the flow velocity within the lesion. If the dynamic gadoliniumenhanced sequences identified flow within the lesion at or preceding the visualization of arterial flow within normal vessels, the lesion is considered to be a high-flow lesion and would exclude diagnosis of KTS. The presence or absence of early venous return from veins draining the lesion or true immediate arterial venous shunting (i.e., an arterial venous malformation) through the lesion is used to describe the flow characteristics.

If the lesion is not apparent on the dynamic gadoliniumenhanced images until the capillary phase, or more typically the venous phase, as determined by a comparison with visualization of normal vessels, the lesion is considered to be a low-flow. In 2002, Van Rijswijk et al. published data from a prospective study resulted from blinding two independent observers as they reviewed conventional MRI and dceMRI imaging performed on 27 patients with clinically suspected high-flow vascular malformations ${ }^{64}$. All patients underwent dceMRI as well as diagnostic angiography. Sensitivity of conventional MRI in differentiating venous and non-venous lesions was $100 \%$.

However, data from this study showed an increase in the specificity of MRI from $24 \%$ - $33 \%$ to $95 \%$ with the addition of dynamic contrast-enhanced sequences. When dceMRI is not definitive in assessing flow status, arteriography is performed not only to confirm the diagnosis, but also to identify the communication pattern with the draining venous system and to provide an opportunity for treatment planning and/or intervention. Although highly specific, arteriography is limited in its ability to delineate a lesion relative to its adjacent anatomic structures. This is an important limitation as malformations can infiltrate muscle, encircle nerves and can invade adjacent vital tissues. In addition arteriography is considered an invasive technique as it carries significant risk for complications including groin hematoma, pseudoaneurysm, arteriovenous fistula, acute arterial thrombo-embolic events and infection. These complications have been reported in approximately $1.5-9 \%$ of patients ${ }^{65,66}$.

The ability to use a single imaging modality to distinguish between high-flow and low flow lesions is essential when the goal is to avoid noncontributory and/or invasive imaging modalities, select proper treatment modality, avoid unnecessary invasive catheterbased procedures and to avoid potentially life threatening side effects. Although multiple imaging modalities are available for the management of KTS, dceMRI provides the most critical information. Above described diagnostic algorithm with novel imaging techniques 
avoids non-contributory imaging and has been validated as clinically applicable for making an accurate anatomical and hemodynamic diagnosis and for treatment planning in majority of patients. In addition, it avoids unnecessary diagnostic arteriograms, in most of the cases, allowing a significant number of patients to be spared the expense, risk, and inconvenience of a catheter-based diagnostic study, as well as delayed or erroneous diagnosis. However it has to be emphasized that dceMRI adds to the cost of the treatment and is currently widely utilized only in high volume hospitals.

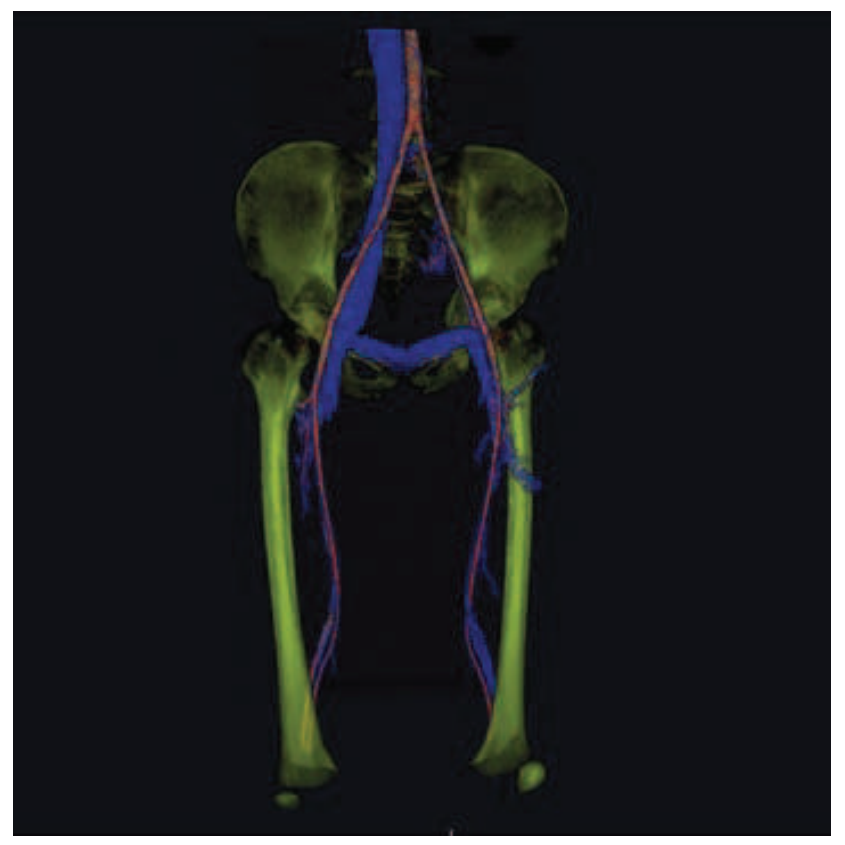

Figure 4 - 3-D MRI reconstruction of a 26-year-old male demonstrates aplasia of the left common iliac vein. Evaluation of patency and anatomical variations of the deep venous system is vital in all KTS patients prior to establishing a definite treatment plan, due to relatively high incidence of deep venous system anomalies.

\section{Discussion}

$\boldsymbol{R}$ Mattassi said that the old triad of 1900, based only on clinical data, is old enough. Today we can perform a more precise diagnosis, which should be a step by step progression of examinations, starting from the less invasive, as following:

\section{Examination tools in KTS}

step by step, starting from the less invasive clinical examination: it is very important that the presence of the triad should NOT bring directly to the diagnosis but only to a suspicion

duplex scan

MRI: some specific settings for main veins demonstration are required

lymphoscintigraphy: to demonstrate main draining lymphatics. That exam should be done not in the standard manner but with separate morphological study of deep and superficial lymphatics

- $\quad$ comparative bone X-Ray to measure limb length difference

other optional test
BB Lee noted that diagnosis to find out or exclude the AVM is based on clinical evaluation/physical exam, basic combination of non-invasive tests like DUS and MR especially when there are other CVMs as well. We postpone further evaluation of AVM with invasive test like arteriography till needed/indicated for the treatment but meanwhile, we do carry CTA and/or trans-arterial lung perfusion scintigraphy $(T L P S)^{67-69}$, etc. to assess its progress, he added.

In selected cases, the edema's composition of the foot could be analysed and might show chylous components or land leaking skin vesicle, losing a milky lymphorrhea, argued JP Belgrado.

BB Lee noted that 'Deep infiltrating veins/ Extratruncular VM' can be combined with Extratruncular LM. Indeed, in his experience, quite a few of extratruncular VM diagnosed with MRI with no contrast was subsequently confirmed, as either combined with extratruncular LM or pure extratruncular LM through MRI with contrast, which he confirmed by direct needle aspiration to check its contents.

\section{Treatment}

The vast majority of practitioners consider hemorrhage, infections, acute thromboembolism and/or refractory ulcerations as absolute indication for treatment. Relative indications include pain, functional impairment, edema (secondary to chronic venous insufficiency), limb asymmetry and/or cosmesis ${ }^{70,71}$. Pretreatment planning for KTS patients is best done by a multidisciplinary vascular malformation team, when possible. Prior to treatment, every effort should be exerted to rule out the arterial component. This differentiation is of critical significance as treatment options for high flow and low flow malformations are significantly different as the presence of arteriovenous shunting represents an absolute contraindication for sclerotherapy due to increased risk of distal embolic events.

Pretreatment planning should routinely incorporate evaluation of patency of the deep and superficial venous system due to the high prevalence of the deep venous system anomalies in KTS patients. In a study of 392 patients Eifert et al. documented aplastic or hypoplastic deep venous trunks in $8 \%$ of vascular malformation patients ${ }^{72}$. The prevalence of deep venous anomalies is even higher $(18 \%)$ in subgroup of patients with KTS. (Figure 4) This assessment needs to be included in the treatment planning since venous blood flow from the affected extremity may depend on the malformation vessels and obliteration or exclusion of the malformation from the circulation carries the risk of the impairment of venous return from the affected extremity. Surgical resection of dilated superficial varicosities in a patient with an absent or hypoplastic deep venous system is disastrous. The remaining venous collateral system is not adequate to drain the limb, and massive lower extremity swelling and ulceration can develop.

The treatment modalities utilized for the management of KTS can be conservative and interventional. 
Compression therapy represents the mainstay for conservative treatment. Most commonly an elastic garment or graded compression stockings are used on the affected extremity, as this has been shown beneficial in managing both lymphedema and/or symptoms of chronic venous insufficiency. In patients with venous edema or chronic lymphoedema physical therapy including massage treatment and intermittent pneumatic compression therapy, has been used with good results.

In addition to this, conservative treatment can be supplemented with local wound care, special orthopedic footwear as well as with lifestyle modification, as these may be needed to improve daily functional capacity of a KTS patient. In addition to somatic symptoms, the psychological aspect of KTS pathology, caused by a visible deformity of the KTS should not be underestimated. Therefore, KTS patients should be offered a psychological counseling, if needed, as well as participation in the KTS support $\operatorname{group}(s)^{42}$. This participation should be offered to both patients and their families.

Only patients who are symptomatic or have absolute indications for the intervention (discussed above) that are refractory to conservative treatment should be considered candidates for therapeutic intervention, given the potential for additional morbidity related to any intervention. The treatment of KTS patients is characterized by multiple treatment sessions, in significant majority of patients, applying the treatment modality that is the most appropriate for the location, extent and morphology of the lesion(s).

The need for multiple treatment sessions should be discussed with a patient and their family (if applicable) prior to initiation of treatment to increase patient's compliance with the therapy. The possibility of recurrence following the treatment should also be discussed with the patient prior to starting the treatment to minimize patients' frustration in case of the recurrence. Goals of the treatment should be preset with each patient individually and successful accomplishment of preset goals marks the completion of treatment, as treatments are frequently palliative and goaloriented, especially in extensive lesions.

Traditionally, surgical resection was effectively used for encapsulated and small lesions. However in patients with diffuse and multifocal lesions, the surgical debulking is relatively contraindicated as damage to surrounding anatomic structures and massive hemorrhage may ensue ${ }^{73}$. In 2016 Malgor et al. retrospectively evaluated long term outcomes of open surgical treatment in 49 patients (53 limbs) with $\mathrm{KTS}^{74}$. The great saphenous vein stripping, lateral embryonic vein, small saphenous vein and accessory saphenous vein surgical removal was performed in 17 $(32 \%), 15(28 \%), 10(19 \%)$ and nine (17\%) lower extremities, respectively. Data from this study showed that two patients developed DVT, one had pulmonary embolism, and one patient had peroneal nerve palsy.

Kaplan-Meier analysis demonstrated that freedom from disabling pain at one, three and five years was $95 \%, 77 \%$ and $59 \%$, respectively. Respective rates for freedom from secondary procedures were $86 \%, 78 \%$ and $74 \%$. In addition, at the last follow-up visit, the venous clinical severity score had decreased from $9.4 \pm 3.27$ to $6.0 \pm 3.20(\mathrm{P}<0.001)$. Data from this study showed that surgical approach in patients with KTS is safe and durable. Although historically surgery has been used to treat vascular malformations associated with KTS over the last two decades, minimally invasive procedures have emerged as effective treatment options.

Sclerotherapy has been used as an effective alternative to surgery in the treatment of venous malformations. Traditionally, the most widely used sclerosant was ethanol. Although effective, data showed that ethanol sclerotherapy was associated with limitations and major complications (local and systemic), including severe pain requiring general anesthesia, ethanol toxicity, and localized tissue necrosis ${ }^{75-77}$. In a study of 87 patients with venous malformations treated with 98 sessions of ethanol sclerotherapy Lee et al. reported outstanding results with $95 \%$ initial success with no recurrence in 71 patients at a mean follow-up of 24 months ${ }^{78}$.

Data from this study also documented complications in $26.7 \%$ of patients which ranged from mild to severe. There were nine cases with ischemic bullae, five with nerve palsy, four cases of transient pulmonary pressure elevation, two with tissue necrosis and tissue fibrosis, one with DVT and one with pulmonary embolism. Of the five nerve palsies, one (affecting the peroneal nerve) was irreversible. Other studies also reported major side effects following ethanol sclerotherapy including cardiac arrest and episodes of transient bradycardia. Ethanol sclerotherapy can also result in transmural vessel necrosis, massive swelling (sometimes resulting in compartment syndrome), depression of the central nervous system, hypertension and pulmonary vasospasm.

Burrows and Mason reported good to excellent results after serial sclerotherapy in $75-90 \%$ of patients with low flow vascular malformations and showed that ethanol injections should be avoided close to major nerves or cutaneous lesions $^{79}$. There was a $12 \%$ complication rate per session and $28 \%$ complication rate per patient in this series, with at least some skin necrosis occurring in $10-15 \%$. Given that liquid sclerosants become diluted by intralesional blood, the use of sclerosants in microfoam form significantly improves the procedure for venous malformations as the foam bubbles displace intralesional blood and prevent sclerosant from becoming diluted. Foam 
bubbles achieve maximal exposure between the sclerosing agent and the endothelial lining of malformation and the echogenicity of the bubbles makes them visible on ultrasonography making the procedure more effective and easier to perform. (Figure 5)

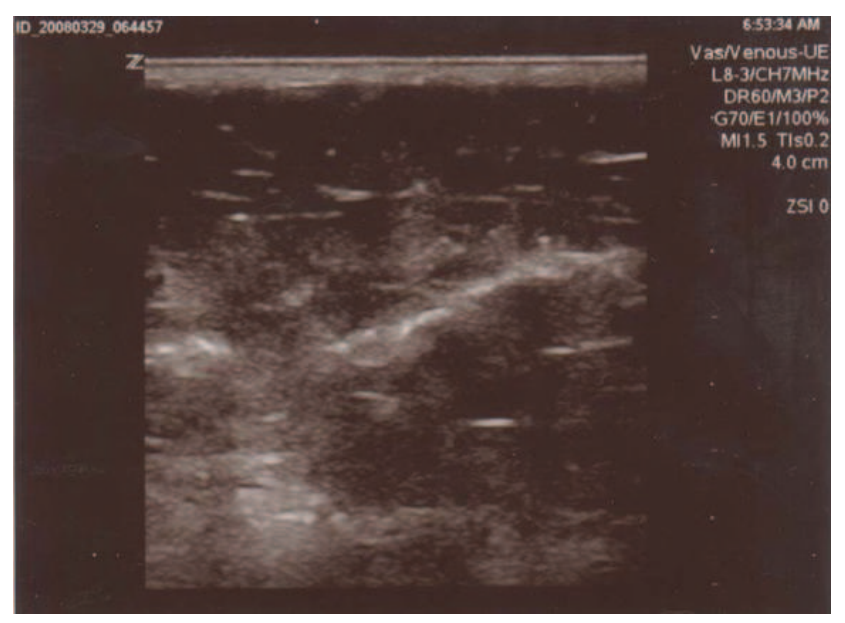

Figure 5 - Ultrasonographic findings during sclerotherapy treatment of low flow, venous malformation in a 21 year old female with KTS. The echogenicity of the bubbles makes them visible on US surveillance making the procedure easier to perform, which is one of the major advantages of foam sclerotherpay as compared to liquid sclerotherapy.

For these reasons foam treatments, in contrast to liquid sclerotherapy, can be performed on ambulatory basis under local anesthesia. In a prospective randomized clinical trial Yamaki et al. compared efficacy of ultrasoundguided foam sclerotherapy with ultrasound-guided liquid sclerotherapy in the treatment of 89 symptomatic venous malformations ${ }^{80}$. Data from this study showed that the amount of sclerosant required to treat the lesion was significantly smaller in patients who were treated with foam sclerotherapy. These properties of sclerosant in the form of microfoam make it possible to use smaller doses in small increments what reduces the risk of side effects and toxicity. Foam can be produced with different techniques that result in differences in bubble size, foam stability and reabsorption rates.

Most widely accepted method for producing stable foam is "Tessari method" first described in $2000^{81}$. The choice of foamed sclerosant is typically physician dependent. Currently the majority of venous malformations are treated with $0.5 \%-1 \%$ sodium tetradecyl sulfate or $1 \%$ polidocanol. Alternative sclerosants such as bleomycin or doxycycline may be used in special circumstances, including malformations with lymphatic component. The first large study of patients treated by foam sclerotherapy was published by Cabrera et al. This study included 50 patients (35 with venous malformations and 15 with
KTS ${ }^{82}$. Sclerotherapy was performed by ultrasound guided injection of $0.25 \%$ to $4 \%$ polidocanol microfoam.

Data from this study showed that the treatment was beneficial in $46(92 \%)$ patients. Total disappearance of treated malformation, reduction in size of more than $50 \%$ and reduction in size of less than $50 \%$ was documented in 158,15 and 13 patients, respectively. In subgroup of patient who presented with pain ( $\mathrm{n}=39), 25$ experienced total relief, and in the remaining 14 patients the pain was significantly reduced. There were no major adverse events. Skin necrosis developed in three patients and four patients developed skin hyperpigmentation that was transient.

Data from another perspective study that included 14 patients (eight with KTS) treated with $1 \%$ or $2 \%$ polidocanol, demonstrated that the use of polidocanol foam sclerotherapy was effective, and showed no major complications, no down time and no need for general or regional anesthesia. Although there is a significant amount of data that showed excellent results by evaluating safety and efficacy of the endothermal treatment either with radiofrequency ablation (RFA) or endovenous laser ablation (EVLA) in patients with chronic venous insufficiency caused by superficial venous reflux disease there are some limitations in KTS patients who have large incompetent superficial veins located immediately under the skin, as treatment of these superficial veins can lead to significant thermal injury.

Although this concern should not be underestimated data from several case reports and smaller case series showed that both RFA and EVLA were efficient and safe treatment for superficial incompetent veins in KTS patients. Frasier et al. showed that combined treatment (RFA and sclerotherapy) was associated with markedly decreased leg pain, edema, and varicose vein appearance in three female KTS patient that were previously unsuccessfully treated with the conservative therapy ${ }^{83}$. In 2014 , Harris et al. showed that RFA can be safely and effectively used for obliteration of perforating veins in KTS patients. Data from this study showed a significant symptomatic improvement following staged and multimodal treatment of perforating veins that included RFA combined with sclerotherapy ${ }^{84}$.

The specific indications for treatment of lateral embryonic vein are based on symptom severity and the status of the deep venous system. In symptomatic patients (i.e. hemorrhage, debilitating pain, and/or functional disability) with patent deep veins, treatment of the lateral embryonic vein is indicated for the elimination of altered hemodynamics without compromising lower extremity blood return. This also applies to a subgroup of patients with hypoplasia of the deep veins: in this case treatment of the lateral marginal vein will lead to spontaneous dilation of the deep veins, and therefore hypoplasia of deep veins 
is not a contraindication for treatment. By contrast, aplasia of the deep veins does represent a contraindication for intervention, as the lateral embryonic vein serves as a major draining vein of the affected limb in these cases. A modified Perthes text could clarify the compensating value of the marginal vein, analyzing its exclusion at different levels. The result can suggest a local surgical therapy.

All patients with a lateral marginal vein should undergo a complete hypercoagulability workup (including measurement of D-Dimer and fibrinogen) and should be anticoagulated appropriately with weight adjusted dose $(100 \mathrm{U} / \mathrm{kg} / \mathrm{d})$ of low molecular weight heparin periprocedurally ${ }^{31}$. Traditionally, as mentioned above, surgical resection of lateral marginal vein is preferred over endovascular treatment modalities as it is safe and durable and due to the superficial location of this vein and the fact that endovenous treatment modalities are associated with the risk of skin damage.

\section{Discussion}

A quarter or more of LM components of the KTS is extratruncular LM/lymphangioma alone as a constant source of lymph leakage especially after ill-planned excision of coexisting marginal vein $(M V)$, where the complication seems to be the effect of the previous balance disrupted by the treatment, affirmed $\boldsymbol{B} B \mathbf{L}$ Lee.

MA Amore declared that LM is often present in KTS, but we must take care in the treatment with the massive use of Rapamycin, owing to the Rapamycin associated lymphedema, lymphocele, chylous ascites... etc. as secondary effect. More interesting Rapamycin was the "STAR" of the last ISSVA meeting held in Buenos Aires one week before the KTrenaunay debate, with a lot of groups around the world with a high follow up of this drug.

$\boldsymbol{B} \boldsymbol{B}$ Lee declared he was so disturbed by sudden enthusiasm on Rapamycin, that transplant surgeon are already fully aware of, about the risk involved with de novo swelling of the limb/lymphedema together with increasing risk of the lymphocele formation following kidney transplantation for many decades. Besides Rapamycin certainly increased delayed wound healing with higher risk of wound disruption in his personal experience.

As regards the surgical treatment, $\boldsymbol{F}$ Passariello reported that in selected cases the surgical therapy has a clear beneficial effect, for instance when an extrinsecal compression on the deep veins increases the symptoms of deep veins KTS hypotrophy. As suggested by Servelle ${ }^{85}$, the resection of fibrous structures can improve considerably symptoms. Compression can be due to abnormal arterial branches or to fibrous arcs, as it occurs in the upper limb with the Langer axillary arc ${ }^{85}$ or in the lower limb with a fibrous-muscular fiber between the two gastrocnemius muscles 86 .

\section{The Chiva Strategy in KTS}

The CHIVA strategy essentially separates the systolic reflux from the diastolic part. Only the diastolic component can be excised in order to preserve the compensating veins ${ }^{87-89}$. The study of the Systo-Diastolic reflux is essential to understand if there is a compensating pathway, which must be respected and if there is a diastolic reflux, which can be safely interrupted. The CHIVA strategy uses the modified Perthes test to select the level of interruption of the marginal vein and to achieve also a naevus reduction.

An accurate ultrasound mapping is performed, together with dynamic tests as Valsalva, Paraná and Perthes, in order to respect the compensating veins in an open vicarious shunts (OVS) and disconnect the diastolic overload of the closed shunts (CS). The surgery is mini-invasive, performed in one or more steps with 6 months interval (time needed to let the system to stabilize) with divisions and non-absorbable ligations at the disconnections sites. Surgery is planned without any excision in order to let the capillary malformation drain properly (reduced coloration) and paying careful attention to the uneasy haemostasis, due to fragile veins and capillary malformation.

The intervention tries to block the diastolic overload, pressures and flows while preserving the draining outflow, in order to ease the skin drainage as well as the reduction of the capillary skin malformation. These are the basics of CHIVA management, whatever the vessels anatomy and the cause of their dysfunction.

Such aimed punctual disconnections prevent large bleedings caused by extended phlebotomies, ease the skin drainage, improve the skin changes and prevent any recurrence. As regards the neavus reduction, it is worth noting that the CHIVA strategy is the first one which links the skin drainage as well as $\mathrm{CM} /$ port wine stain to MV drainage, as we know of. This observation/ hypothesis is certainly a new area to be included into future research projects together with unintentionally neglected $\mathrm{CM}$ altogether with microcirculation at tissue level.

\section{Summary}

Over the last two decades there has been a significant progress in the understanding of molecular and genetic mechanisms responsible for etiology and pathophysiology of KTS as well as significant improvement in the management of these patients. Data from numerous studies provide strong evidence that experienced providers working in the context of a coordinated and structured multidisciplinary vascular malformation team can offer the most efficient management of KTS patients. Diagnostic algorithm utilized to exclude presence of arterial flow is clinically applicable for making an accurate diagnosis and pretreatment planning in majority of patients. For most patients with minimal symptoms conservative treatment seems to be the best strategy. Patients with more severe symptomatic require treatment. Choice of treatment modality depends upon lesion's location, extent and morphologic as well as hemodynamic characteristics. This management algorithm for KTS results in favorable outcomes with reasonable complication rates in this 
frequently challenging group of patients. New expectations come from the CHIVA approach to vascular malformations, which detects the systolic and diastolic components of reflux, in order to perform selective and short venous excisions. The method is considered an effective one, though an adequate training is required.

\section{Acknowledgements}

The KTrenaunay Vasculab Debate was organized by the Vasculab List as an Online Debate. We thank all the participants for their contribution and especially for their active role: Miguel Angel Amore, Pier Luigi Antignani, Iris Baumgartner, Jean-Paul Belgrado, Lena Blomgren, Alun H Davies, Tom Eaton, Stefano Ermini, Claude Franceschi, SB Gogia, Byung Boong Lee, NingFei Liu, Jovan N Markovic, Raul Mattassi, Nick Morrison, Tom O'Donnell, Waldemar L Olszewski, Sandeep Raj Pandey, Kurosh Parsi, Hugo Partsch, Fausto Passariello, Malay Patel, Sergio Pillon, Teresa Pintos Moreu, Cestmir Recek, Heraldo Schlup, Eva M Sevick, Natarajan Sekar, Gerard Stansby, Massimo Vaghi, David Wright. effort.

Finally, we thank Mrs. Iolanda Palma for her organizational

\section{References}

1) Geoffroy Saint-Hilaire I. Histoire générale et particulière des anomalies de l'organisation chez l'homme et les animaux. 3 volumes + atlas. Paris, J.M.; Baillère édit., 1832-7. Available on line at the address http://www.biodiversitylibrary.org/item/106438\#page/768/ mode/lup at the date of Feb 8, 2017.

2) Morin A. 1996, "La tératologie de Geoffroy Saint-Hilaire á nos jours" [The teratology of Geoffroy Saint-Hilaire nowadays]. Bulletin de l'Association des Anatomistes, 80, 248:17-31.

3) You CK, Rees J, Gillis DA, et al. Klippel-Trenaunay syndrome: a review. Can J Surg. 1983;26:399-403.

4) Trelat U, Monod A. De l\#hypertrophie unilaterale partielle ou totale du corps. Arch Gen Med. 1869;13:536 -538.

5) Klippel M, Trenaunay P. Memoires originaux : du naevus variqueux osteo-hypertrophique. Arch Gen Med. 1900;Tome III:641672.

6) Parkes Weber F. Angioma formation in connection with hypertrophy of limbs and hemi-hypertrophy. Br J Dermatol. 1907;19:231-235.

7) Aelvoet GE, Jorens PG, Roelen LM. 1992. Genetic aspects of the Klippel-Trenaunay syndrome. Br J Dermatol 126:603-607.

8) Oduber CE, van der Horst CM, Hennekam RC. 2008. KlippelTrenaunay syndrome: Diagnostic criteria and hypothesis on etiology. Ann Plast Surg 60:217-223. 1974.

9) Malan E. Vascular Malformations. Carlo Erba ed. Milan,

10) Lorda-Sanchez I, Prieto L, Rodriguez-Pinilla E, MartinezML. 1998. Increased parental age and number of pregnancies in Klippel-Trenaunay-Weber syndrome. Ann Hum Genet 62:235-239.

11) Jorgenson R, Darby B, Patterson R, Trimmer K. Prenatal diagnosis of the Klippel-Trenaunay-Weber syndrome. Pren Diag 1994;14:989-92.
12) Lindenauer SM. The Klippel-Trenaunay syndrome: varicosity, hypertrophy and hemangioma with no arteriovenous fistula. Ann Surg. 1965;162:303-314.

13) Berry SA, Peterson C, Mize W, et al. Klippel-Trenaunay syndrome. Am J Med Gen 1998;79:319-26

14) Hanahan D. Signaling vascular morphogenesis and maintenance. Science 1997;277:48-50.

15) Klagsbrun M, D\#Amore PA. Vascular endothelial growth factor and its receptors. Cytokine Growth Factor Rev 1996;7:259-70.

16) Whelan AJ, Watson MS, Porter FD, et al. KlippelTrenaunay-Weber syndrome associated with a 5:11 balanced translocation. Am J Med Genet. 1995;59:492- 494.

17) Wang Q, Timur AA, Szafranski $P$, et al. Identification and molecular characterization of de novo translocation $\mathrm{t}(8 ; 14)(\mathrm{q} 22.3 ; \mathrm{q} 13)$ associated with a vascular and tissue overgrowth syndrome. Cytogenet Cell Genet. 2001;95:183-188.

18) Timur AA, Sadgephour A, Graf M, et al. Identification and molecular characterization of a de novo supernumerary ring chromosome 18 in a patient with Klippel-Trenaunay syndrome. Ann Hum Genet. 2004;68:353-361.

19) Eerola I, Boon LM, Mulliken JB, et al. Capillary malformation-arteriovenous malformation, a new clinical and genetic disorder caused by RASA1 mutations. Am J Hum Genet 2003;73:1240-9.

20) Revencu N, Boon LM, Dompmartin A, Rieu P, Busch WL, Dubois J, Forzano F, van Hagen JM, Halbach S, Kuechler A, Lachmeijer AMA, Lähde J, Russell L, Simola KOJ, Mulliken JB, Vikkula M. 2013. Germline mutations in RASA1 are not found in patients with Klippel-Trenaunay syndrome or capillary malformation with limb overgrowth. Mol Syndromol 4:173-178.

21) Vahidnezhad H, Youssefian L, Uitto J. 2016. KlippelTrenaunay syndrome belongs to the PIK3CA-related overgrowth spectrum (PROS). Exp Dermatol 25:17-19.

22) Wullschleger $\mathrm{S}$, Loewith R, Hall MN TOR signaling in growth and metabolism. Cell 2006;124:471-484.

23) Bessis D, Vernhet H, Bigorre M, Quéré I, Rössler J. Life-Threatening Cutaneous Bleeding in Childhood Klippel-Trenaunay Syndrome Treated With Oral Sirolimus. Jama Dermatology, published online May 11, 2016, E1-2, DOI: 10.1001/jamadermatol.2016.1008.

24) Fernandez-Pineda I, Marcilla D, Downey-Carmona FJ, Roldan S, Ortega-Laureano L, Bernabeu-Wittel J. Lower Extremity Fibro-Adipose Vascular Anomaly (FAVA): A New Case of a Newly Delineated Disorder. Ann Vasc Dis. 2014;7(3):316-319. DOI: 10.3400/ avd.cr.14-00049.

25) Luks et al. Lymphatic and Other Vascular Malformative/ Overgrowth Disorders Are Caused by Somatic Mutations in PIK3CA. J Pediatr 2015;166:1048-54.

26) Vignot S, Faivre S, Aguirre D, et al. mTOR-targeted therapy of cancer with rapamycin derivatives. Ann Oncol 2005;16:525-537.

27) Dimopoulos A, Sicko RJ, Kay DM, Rigler SL, Fan R, Romitti PA, Browne ML, Druschel CM, Caggana M, Brody LC, Mills JL. 2017. Copy number variants in a population-based investigation of Klippel-Trenaunay syndrome. Am J Med Genet Part A 173A:352-359.

28) Shikauchi Y, Saiura A, Kubo T, Niwa Y, Yamamoto J, Murase Y, Yoshikawa H. SALL3 Interacts with DNMT3A and 
Shows the Ability To Inhibit CpG Island Methylation in Hepatocellular Carcinoma. Molecular and Cellular Biology, 2009 Apr;1944-58.

29) Liu NF, Lu Q, Yan ZX. Lymphatic malformation is a common component of Klippel-Trenaunay syndrome. JVS. 2010 Dec;62(6):1558-63. DOI: $\underline{10.1016 / j . j v s .2010 .06 .166 . ~}$

30) Mulliken JB, Young AE, eds. Vascular Birthmarks: Hemangiomas and Malformations. Philadelphia: WB Saunders, 1988.

31) Lee BB, Baumgartner I, Berlien P, Bianchini G, Burrows $P$, Gloviczki P, Huang, Y, Laredo J, Loose DA, Markovic JN, Mattassi R, Parsi K, Rabe E, Rosenblatt M, Shortell C, Stillo F, Villavicencio L, Zamboni P. Guidelines: Diagnosis And Treatment of Venous Malformations. Consensus Document of the International Union of Phlebology (IUP). Int Angiol. Jun, 2014.

32) Mulliken JB, Glowacki J (1982) Hemangiomas and vascular malformations in infants and children.A classification based on endothelial characteristics. Plast Reconstr Surg 69:412-422.

33) Belov S. Classification, terminology, and nosology of congenital vascular defects. In: Belov S, Loose DA, Weber J, eds. Vascular Malformations. Reinbek, Germany: Einhorn-Presse; 1989:25-30.

34) Lee BB, Bergan J. Gloviczki P, Laredo J, Loose DA, Mattassi R, Parsi K, Villavicencio JL, Zamboni P: Diagnosis and treatment of venous malformations - Consensus Document of the International Union of Phlebology (IUP)-2009. International Angiology 2009 December;28(6):434-51

35) Mattassi R. Management of combined venous and lymphatic malformations. Phlebolymphology. 2016;23(2):112-20. Available at the address http://www.phlebolymphology.org/phlebolymphology-89/ at the date of Mar 23, 2017.

36) Blei F. Medical management (Chylorrea). In Lee BB et al. (eds.), Lymphedema, chapter 54, 449. Springer-Verlag London Limited 2011. DOI: $10.1007 / 978-0-85729-567-554$.

37) Azizkhan RG, Taylor JA. Surgical Management (Chylorrea). In Lee BB et al. (eds.), Lymphedema, chapter 55, 455. Springer-Verlag London Limited 2011. DOI: 10.1007/978-0-85729-567-5 55.

38) Baskerville PA, Ackroyd JS, Lea TM, Browse NL. The Klippel-Trenaunay syndrome: clinical, radiological and haemodynamic features and management. Br J Surg 1985;72:232-6

39) Upadhyay H, Sherani K, Vakil A, Babury M. A case of recurrent massive pulmonary embolism in Klippel-Trenaunay-Weber syndrome treated with thrombolytics. Respiratory Medicine Case Reports. 2016;17:68-70. DOI: 10.1016/j.rmcr.2016.01.008.

40) Li T, Hu SY, Chen ZT, Chen ZQ, Zhi XT. Colorectal cavernous hemangioma in Klippel-Trenaunay syndrome: a rare cause of abdominal pain and hematochezia. Surgery. 2015;157(2):402-4.

41) Servelle M. Klippel Trenaunay syndrome: 768 operated cases. Ann Surg 1985;201:365-73.

42) Gloviczki P, Driscoll DJ. Klippel-Trenaunay syndrome: current management. Phlebology 2007; 22: 291-8.

43) Jacob AG, Driscoll DJ, Shaughnessy WJ, Stanson AW, Clay RP, Gloviczki P. Klippel-Trenaunay syndrome: spectrum and management. Mayo Clin Proc 1998; 73:28-36.

44) Garg L, Mittal UK, Puri SK, Rissam HK. Klippel-Trenaunay syndrome, an unusual association with persistent lateral marginal vein of Servelle: colour Doppler and 256 dual-source MDCT evaluation. BMJ Case Rep. 2015.

45) Bucek RA, Vavrik J, Minar E, Lammer J, Tscholakoff D. Images in cardiovascular medicine. Multimodality imaging of hemangiectasia hypertrophicans (Klippel-Trenaunay-Parkes-Weber syndrome). Circulation. 2004;110(10):e295.

46) Trapanotto V, Hamper UM, DeJong MR, Sheth S. KlippelTrenaunay-Weber syndrome: three-dimensional sonographic imaging. AJR Am J Roentgenol. 1996;166(2):472.

47) Roebuck DJ, Howlett DC, Frazer CK, Ayers AB. Pictorial review: the imaging features of lower limb Klippel-Trenaunay syndrome. Clin Radiol. 1994;49(5):346-50.

48) Trop I, Dubois J, Guibaud L, et al. Soft-tissue venous malformations in pediatric and young adult patients: diagnosis with Doppler US. Radiology. 1999;212:841-845.

49) Franceschi C. Theorie et pratique de la (C)ure (H)emodynamique de 1' (I)nsuffisance (V)eineuse en (A)mbulatoire. Éditions de l'Armancon, Precy-sous-Thyl, 1988.

50) Franceschi C. Le malformazioni vascolari congenite. Part II. p 161-192. In Angiodisplasie. Flebologia. 1997; VIII(3):137-192.

51) Franceschi C, Cappelli M, Ermini S, Gianesini S, Mendoza E, Passariello F, et al. CHIVA: hemodynamic concept, strategy and results. Int Angiol 2016;35:8-30.

52) Franceschi C, Delfrate R, Bahnini A, Laurian C, Bricchi M, Massoni Cl, Birsdorff A. Venous Malformation. Pathophysiology, hemodynamic assessment and treatment strategy. Part 1. Presented at the 1st International Haemodynamic Symposium on Venous Disorders. Milan, 2015.

53) Franceschi C, Delfrate R, Bahnini A, Laurian C, Bricchi $\mathrm{M}$, Massoni Cl, Birsdorff A. Venous Malformation. Pathophysiology, hemodynamic assessment and treatment strategy. Part 2. Presented at the 1st International Haemodynamic Symposium on Venous Disorders. Milan, 2015.

54) Franceschi C, Zamboni P. Principles of Venous Hemodynamics. New York: Nova Science Publishers, 2009.

55) Systo-Diastolic. A Vasculab On Line Event (Jan 12th - 22nd, 2013). DOI: $\underline{10.24019 / 2016 . \text { Systodiastolic }}$

56) Morrison N. [KTrenaunay Debate Vasculab Message Archive. May 1-28, 2016. DOI: 10.24019/2016.KTrenaunay] - Treatment of the Marginal Vein. Msg 11170, May 19, 2016. https:/it.groups.yahoo.com/neo/groups/vasculab/conversations/ messages/11170, May 19, 2016. Accessed on line on Mar 23, 2017. A (free) subscription is required.

57) Laaengh Massoni C, Betroune K, Laurian V, Paraskevas N, Bisdorff A, Franceschi C. Varicose veins and venous malformations of the lower limbs. Duplex US assessment of the venous drainage and compensatory veins test. Presented to the 50th Congrès du College Français de Pathologie Vasculaire, Paris 2016.

58) Franceschi C. [KTrenaunay Debate Vasculab Message Archive. May 1-28, 2016. DOI: 10.24019/2016.KTrenaunay] Treatment of the Marginal Vein. . Msg 11186, May 20, 2016. https://it.groups.yahoo.com/neo/groups/vasculab/conversations/ messages/11186, May 20, 2016. Accessed on line on Mar 23, 2017. A (free) subscription is required.

59) Rauch RF, Silverman PM, Korobkin M et al. Computed tomography of benign angiomatous lesions of the extremities. J Comput Assist Tomogr 1984; 8:1143-46. 
60) Konez O, Burrows PE. Magnetic resonance of vascular anomalies. Magn Reson Imaging Clin N Am. 2002;10(2):363-88.

61) Van Rijswijk CS, van der Linden E, van der Woude HJ, van Baalen JM, Bloem JL.Value of dynamic contrast-enhanced MR imaging in diagnosing and classifying peripheral vascular malformations. AJR Am J Roentgenol. 2002 ;178(5):1181-7.

62) Markovic JN, Kim CY, Lidsky ME, Shortell CK. A 6-year experience treating vascular malformations with foam sclerotherapy. Perspect Vasc Surg Endovasc Ther. 2012;24(2):70-9.

63) Lidsky M, Spritzer C, and Shortell C. The role of dynamic contrast-enhanced magnetic resonance imaging in the diagnosis and management of patients with vascular malformations. J Vasc Surg. I 2011;53(1):131-137.

64) van Rijswijk CS, van der Linden E, van der Woude HJ, van Baalen JM, Bloem JL. Value of dynamic contrast-enhanced MR imaging in diagnosing and classifying peripheral vascular malformations. AJR Am J Roentgenol 2002;178:1181-7.

65) Lumsden A, Peden E, Bush RL, Lin PH.Complications of endovascular procedures. In: Vascular Surgery. Rutherford RB (Ed.). Elsevier Saunders, PA, USA, 809-820, 2005.

66) Nasser TK, Mohler ER 3rd, Wilensky RL, Hathaway DR. Peripheral vascular complications following coronary interventional procedures. Clin. Cardiol. 18(11), 609-614, 1995.

67) Lee BB, Choe YH, Ahn JM, Do YS, Kim DI, Huh $\mathrm{SH}$, Byun $\mathrm{HS}$. The new role of magnetic resonance imaging in the contemporary diagnosis of venous malformation: can it replace angiography? Jamcollsurg. 2004 Apr;198(4):549-558. DOI: 10.1016/ j.jamcollsurg.2003.12.013.

68) Lee BB, Mattassi R, Kim YW, Kim BT, Park JM, Choi JY. Advanced management of arteriovenous shunting malformation with transarterial lung perfusion scintigraphy for follow-up assessment. International Angiology. 2005 Jul;24(2):173-84.

69) Chung HW, Choi JY, Kim YW. Diagnosis and PostTherapeutic Evaluation of Arteriovenous Malformations in Extremities Using Transarterial Lung Perfusion Scintigraphy. Nucl Med Mol Imaging 2006;40(6):316-321.

70) Sung HM, Chung HY, Lee SJ, Lee JM, Huh S, Lee JW, et al. Clinical Experience of the Klippel-Trenaunay Syndrome. Arch Plast Surg. 2015; 42(5):552-8.

71) Lee A, Driscoll D, Gloviczki P, Clay R, Shaughnessy W, Stans A. Evaluation and management of pain in patients with KlippelTrenaunay syndrome: a review. Pediatrics. 2005;115(3):744-9.

72) Eifert S, Villavicencio JL, Kao TC, Taute BM, Rich NM. Prevalence of deep venous anomalies in congenital vascular malformations of venous predominance. J Vasc Surg 2000;31:462-71.

73) Gloviczki P, Stanson AW, Stickler GB, Johnson CM, Toomey BJ, Meland NB, et al. Klippel-Trenaunay syndrome: the risks and benefits of vascular interventions. Surgery. 1991;110(3):469-79.

74) Malgor RD, Gloviczki P, Fahrni J, Kalra M, Duncan AA, Oderich GS, et al. Surgical treatment of varicose veins and venous malformations in Klippel-Trenaunay syndrome. Phlebology. 2016;31(3):209-15.
75) Villavicencio JL. Primum non nocere: is it always true? The use of absolute ethanol in the management of congenital vascular malformations. J Vasc Surg 2001; 33: 904-6.

76) Yakes WF, et al., Symptomatic vascular malformations: ethanol embolotherapy. Radiology, 1989. 170(3 Pt 2): p. 1059-66.

77) Yakes WF, Baker R. Cardiopulmonary collapse: sequelae of alcohol embolotherapy. Radiology 1993;189:145.

78) Lee BB, DI Kim, et al. New experiences with absolute ethanol sclerotherapy in the management of a complex form of congenital venous malformation. J Vasc Surg 2001. 33(4): 764-772.

79) Burrows PE, Mason KP. Percutaneous treatment of low flow vascular malformations. J Vasc Interv Radiol 2004; 15: 431-45.

80) Yamaki T, Nozaki M, Sakurai H, Takeuchi M, Soejima K, Kono T: Prospective randomized efficacy of ultrasound-guided foam sclerotherapy compared with ultrasound-guided liquid sclerotherapy in the treatment of symptomatic venous malformations. J Vasc Surg 2008; 47: 578-584.

81) Tessari L, Cavezzi A, Frullini A. Preliminary experience with a new sclerosing foam in the treatment of varicose veins. Dermatol Surg 2001;27:58-60.

82) Cabrera J, Cabrera J, Garcia-Olmedo MA, Redondo P Treatment of venous malformations with sclerosant in microfoam form. Arch Dermatol. 2003;139:1494-6.

83) Frasier K, Giangola G, Rosen R, Ginat DT. Endovascular radiofrequency ablation: a novel treatment of venous insufficiency in Klippel-Trenaunay patients. J Vasc Surg. 2008;47(6):1339-45.

84) Harrison C, Holdstock J, Price B, Whiteley M. Endovenous radiofrequency ablation and combined foam sclerotherapy treatment of multiple refluxing perforator veins in a Klippel-Trenaunay syndrome patient. Phlebology. 2014;29(10):698-700.

85) Servelle M. Malformations congénitales des veines des membres. In "Pathologie Vasculaire. 2. Les Affections Veineuses." [Congenital Malformations of limb veins. In "Vascular Pathology. 2. Venous Diseases."] 1978. Masson. p. 23-109.

86) Tramontano R, Pane G, Gallucci A, Passariello F, Aliperta D. La sindrome di Klippel-Trenaunay-Servelle: Considerazioni su di un caso osservato. [The Syndrome of Klippel-Trenaunay-Servelle: Notes about a clinical case.] Presented to the $7^{\text {th }}$ International Meeting of Phlebology (Copenhagen, 1980). La Riforma medica 1982 Sep;97(9):535-8.

87) Franceschi C. Les malformations vasculaires congénitales. [Congenital Vascular Malformations] In "Encyclopédie pratique d'échotomographie et de Doppler vasculaire". Paris, 1994. Editions LEN Médical, Paris. 1995.

88) Laurian C, Enjolras O, Bisdorff A, Franceschi C, Marteau V. Hémangiomes et malformations vasculaires [Hemangiomes and Vascular Malformations] - 21/03/14. EMC Encyclopédie MédicoChirurgicale [43-265] - DOI : 10.1016/S0246-0459(14)67383-4.

89) Laurian C, Franceschi C, D Herbreteau D, Enjolras O. Traitement chirurgical des malformations vasculaires des membres [Surgical Treatment of Vascular Malformations of the limbs]. EMC - Encyclopedie Médico-Chirurgicale - Chirurgie. Paris, Apr 2004. 01/01/04 [43-260] 